\title{
1 Novel roles of Kinesin-13 and Kinesin-8 during cell growth and division in the
} 2 moss Physcomitrella patens

4 Shu Yao Leong, Tomoya Edzuka, *Gohta Goshima, and *Moé Yamada

6 Division of Biological Science, Graduate School of Science, Nagoya University, Furo-cho,

7 Chikusa-ku, Nagoya 464-8602, Japan

8

*Corresponding authors: yamada.moe@a.mbox.nagoya-u.ac.jp; goshima@bio.nagoya-u.ac.jp

Short title: Kinesin-13 and Kinesin-8 in mitosis and tip-growth

14 One sentence summary: This study uncovered the roles of Kinesin-13 and Kinesin- 8 in regulating

15 microtubule dynamics for mitotic spindle formation and straight tip cell growth in the moss

16 Physcomitrella patens

The authors responsible for distribution of materials integral to the findings presented in this article in

20 accordance with the policy described in the Instructions for Authors (www.plantcell.org) are: Moé

21 Yamada (yamada.moe@a.mbox.nagoya-u.ac.jp) and Gohta Goshima (goshima@bio.nagoya-u.ac.jp). 


\begin{abstract}
24 Abstract
25

Kinesin-13 and -8 are well-known microtubule (MT) depolymerases that regulate MT length and chromosome movement in animal mitosis. While much is unknown about plant Kinesin-8, Arabidopsis and rice Kinesin-13 have been shown to depolymerise MTs in vitro. However, mitotic function of both kinesins has yet to be understood in plants. Here, we generated the complete null mutants in plants of Kinesin-13 and -8 in the moss Physcomitrella patens. Both kinesins were found to be non-essential for viability, but the Kinesin-13 knockout (KO) line had increased mitotic duration and reduced spindle length, whereas the Kinesin- $8 \mathrm{KO}$ line did not display obvious mitotic defects. Surprisingly, spindle MT poleward flux, for which Kinesin-13 is responsible for in animals, was retained in the absence of Kinesin-13. Concurrently, MT depolymerase activity of either moss kinesins could not be observed, with MT catastrophe inducing (Kinesin-13) or MT gliding (Kinesin-8) activity observed in vitro. Interestingly, both KO lines showed waviness in their protonema filaments, which correlated with positional instability of the MT foci in their tip cells. Taken together, the results suggest that plant Kinesin-13 and -8 have diverged in both mitotic function and molecular activity, acquiring new roles in regulating MT foci positioning for directed tip-growth.
\end{abstract}

Key words: Physcomitrella patens, mitosis, microtubule foci, microtubule dynamics, tip-growth, Kinesin-13, Kinesin-8

Running title: Kinesin-13 and Kinesin-8 in mitosis and protonema tip-growth

\title{
Introduction
}

Microtubule (MT)-based motor proteins, Kinesins, form a large superfamily in animal and plant species (61 genes in Arabidopsis thaliana, 78 in Physcomitrella patens, 45 in Homo sapiens, and 25 in Drosophila melanogaster) (Reddy and Day, 2001; Miki et al., 2005; Shen et al., 2012). Kinesins show various activities in association with MTs and play pivotal roles in eukaryotic cells, such as cargo transport, MT organisation, MT dynamics regulation, and force generation (Walczak and Heald, 2008; Hirokawa et al., 2009). Comprehensive functional analysis in several animal model systems, such as fly and human cell lines, frog egg extracts, and mouse, together with biochemical characterisation of each kinesin motor have provided insights into how MT-based intracellular processes are driven and regulated during cell proliferation, differentiation, and animal development. In contrast, cellular and developmental function of plant kinesins are less clear, partly due to the difficulty in making and characterising the phenotypes of complete knockout $(\mathrm{KO})$ lines of paralogous kinesins that likely 
function redundantly. The use of high-resolution live microscopy, which was particularly critical for assessing kinesin functions during mitosis in animals, has also been limited in plants.

Within the kinesin superfamily, Kinesin-13 and Kinesin- 8 commonly show a unique activity in vitro: MT depolymerisation (Desai et al., 1999; Howard and Hyman, 2007; Walczak et al., 2013). In vivo, Kinesin-13 is able to depolymerise relatively stable MTs from both ends while MT catastrophe inducing activity is limited to the plus-end (Rogers et al., 2004; Mennella et al., 2005). The best-studied Kinesin-13, human KIF2C/MCAK, accumulates at MT ends either by diffusion or through recruitment by other MAPs (Lee et al., 2008). At the ends, it binds to and stabilises protofilament bends, which promotes strain on the association between protofilaments within the MT lattice (Moores et al., 2002; Ovechkina et al., 2002; Ogawa et al., 2017). In the mitotic spindle, KIF2C/MCAK is localised to the kinetochore and likely triggers depolymerisation of MT plus-ends that are erroneously attached to the kinetochore (Kline-Smith et al., 2004; Walczak et al., 2013). Another Kinesin-13 (human KIF2A, fly KLP10A) localises at the pole region and depolymerises MTs, including relatively stable kinetochorebound MTs, from the minus-end, driving poleward movement of MTs (called spindle MT poleward flux) and chromosome segregation at anaphase (Rogers et al., 2004; Ganem et al., 2005; Walczak et al., 2013). Depletion of Kinesin-13 causes various mitotic errors, such as spindle elongation, spindle monopolarisation, erroneous kinetochore-MT attachment, and chromosome lagging at anaphase (Walczak et al., 2013).

While Kinesin-13 does not show motility on MTs, Kinesin- 8 possesses both MT depolymerising activity and processive plus-end directed motility, and thus preferentially destabilises MT plus-ends (Howard and Hyman, 2007; Walczak et al., 2013). During mitosis, Kinesin-8 concentrates at the outer kinetochore region and prevents excessive elongation of kinetochore MTs and stabilises this kinetochore-MT attachment to promote chromosome alignment to the spindle equator (Mayr et al., 2007; Stumpff et al., 2008; Stumpff et al., 2012; Edzuka and Goshima, 2019). As a whole, Kinesin-13 and -8 MT depolymerisation activity is generally required for proper MT length regulation and correct chromosome movement during mitosis of various animal cell types (Walczak et al., 2013). This mitotic activity extends to cytokinesis, where Kinesin-13 and -8 also control anaphase spindle length and bundling, respectively (Gatt et al., 2005; Uehara et al., 2013). Kinesin-13 and -8 are also repurposed for interphase where mouse KIF2A (Kinesin-13) suppresses excessive axonal outgrowths (Homma et al., 2003), and KIF24 (Kinesin-13) and KIF19 (Kinesin-8) have roles in regulating primary cilia formation and cilia length, respectively (Kobayashi et al., 2011; Niwa et al., 2012).

Despite protein conservation, the function and activity of Kinesin- 13 and -8 are not fully understood in plants. Neither mutant phenotypes nor biochemical activity have been reported for Kinesin-8. On the other hand, rice and Arabidopsis Kinesin-13s have been shown to preserve some 
94 In Arabidopsis thaliana xylem vessel elements, Kinesin-13A is essential to create MT deficient areas in the cortical MT network that is utilised as a scaffold for cellulose synthase movement. Cellulose is deposited only at areas with patterned MTs, thus creating cellulose -lacking regions in MT deficient areas, called pits, allowing for lateral transport of solutes and liquids in the plant. Knockdown of Kinesin-13A by RNAi results in loss of MT patterning and smaller secondary cell wall pit formation (Oda and Fukuda, 2013). Rice Kinesin-13A was shown to be important in regulating MT dynamicity and organisation of the cortical MT network in a variety of cell types (Deng et al., 2015). However, potency of the depolymerisation activity is uncertain, since plant Kinesin-13 lacks a domain required for the robust activity of animal Kinesin-13 (Ovechkina et al., 2002; Lu et al., 2005) (Figure 1A comparing animal and plant domains) and because overexpression of Kinesin-13A in non-xylem cells did not depolymerise MTs unless coexpressed with an additional binding partner MIDD1 (Oda and Fukuda, 2013). On the other hand, Kinesin-13's function during mitosis is unknown as the Kinesin-13A mutants in Arabidopsis and rice did not show mitotic defects. Moreover, Arabidopsis Kinesin-13s have been suggested to be functionally redundant as complete null mutants were embryonic lethal (Fujikura et al., 108 2014).

109 In the present study, the moss Physcomitrella patens, a model basal plant system, was used to 110 investigate Kinesin-13 and -8 function in general cellular processes, such as cell division. Using 111 homologous recombination and CRISPR gene editing techniques, all three paralogues of Kinesin-13 112 and -8 were knocked out, generating viable complete null mutants for each of the kinesin subfamilies.

113 We demonstrated that Kinesin-13 has a mitotic role in plants with Kinesin-13 triple KO line having 114 longer prometaphase duration. However, spindle MT flux was still observed and shorter metaphase 115 spindles than the control were formed in the KO lines. In contrast, Kinesin- 8 triple KO line did not 116 display mitotic phenotypes. Unexpectedly, neither kinesin was shown to actively depolymerise MTs in 117 vitro; Kinesin-13 motor domain was able to induce MT catastrophe, while gliding activity of the 118 Kinesin-8 motor domain was confirmed. Notably, both KO lines had wavy protonema filaments, which 119 correlated with the MT foci abnormally fluctuating at the cell tip. Taken together, functional analyses of 120 Kinesin-13 and Kinesin-8 KO in moss revealed a divergence in mitotic function and molecular activity, while revealing a novel role in regulating MT positioning for directed tip-growth. 


\section{Results}

125

126

Kinesin-13 affects protonema growth, but not gametophore morphology

127

To investigate Kinesin-13's role in the moss Physcomitrella patens, all three paralogous Kinesin-13 genes (Kinesin-13a,-13b, -13c) (Figure 1B) were sequentially deleted by homologous recombination mediated gene replacement in the moss lines expressing GFP-tubulin and histoneH2B-mRFP (Figure S1A, B). Kinesin-13 single and double KO moss colonies did not have observable developmental defects. Moreover, Kinesin-13 triple KO lines (hereafter Kinesin-13 KO) were successfully generated, indicating that Kinesin-13s are not essential genes in moss. There was an overall reduction in colony size in the Kinesin-13 KO when compared to the control (Figure 2A, 2B). However, the overall morphology of the protonema colonies, gametophore (leafy shoots encasing gametangia), and rhizoids (root-like filamentous cells differentiated from gametophore basal cells) (Cove, 2005; Menand et al., 2007; Kofuji and Hasebe, 2014) were indistinguishable from the control (Figure 2A, C), which differs from the case of rice Kinesin-13A mutant that shows small and round grains with shortened panicles and internodes of the whole rice plant (Kitagawa et al., 2010).

To further investigate the colony growth phenotype in the Kinesin- $13 \mathrm{KO}$ moss, early stage moss colonies regenerated from single protoplasts cultured for 8 days were analysed for non-apical cell length and protonema filament branching pattern (Figure 2D-G). Non-apical cells, which undergo little cell expansion after cell division, were found to be shorter in the Kinesin-13 KO moss caulonema cells (Figure 2E, F), consistent with reduced cell length in rice Kinesin-13A mutants (Deng et al., 2015). The branching pattern was analysed by measuring the parameters of branching distance (distances from tip of protonema filament to the first three branching sites), branch filament length, and branch angle (Figure 2E). While the first branching distance (distance from tip of protonema filament to nearest branching site) increased in the Kinesin-13 KO line, other branching pattern parameters were not observably different from that of the control (Figure $2 \mathrm{G}$ ).

Kinesin-13 facilitates spindle MT organisation and chromosome alignment, but does not drive

\section{spindle MT flux}

The protonema tissue propagates by concerted asymmetric cell division and tip-growth in their apical stem cells (Rounds and Bezanilla, 2013). Therefore, a reduction in colony size in the Kinesin-13 KO moss could be attributed to a defect in either or both events. To study mitosis in the Kinesin-13 KO moss, localisation of moss Kinesin-13s to the mitotic spindle was first confirmed. As previously reported (Miki et al., 2014), moss Kinesin-13s showed spindle localisation, most enriched at the spindle equator, with the level of expression varying amongst the three paralogues; they did not show punctate 
159 lapse imaging of moss protonema cells revealed that MT-dependent nuclear movement in prophase

160 was abnormal in the Kinesin-13 KO line. In the control, nuclear movement is minimal or mildly

161 apically directed as cells undergo nuclear envelope breakdown (NEBD). In contrast, in the KO line, the

162 nucleus displayed severe retrograde movement leading up into NEBD and often continued moving

163 basally even during spindle establishment (Figure 3A, B). This retrograde nuclear movement was also

164 observed in the Kinesin-13ac double KO lines to a lesser degree, but not in the single or Kinesin-13ab

165 double KO lines (Figure 3B). Additionally, overexpression of Kinesin-13b(full-length)-Cerulean under

166 the EF1 $\alpha$ promoter complemented the retrograde nuclear movement (Figure 3C, D). However, mutant

167 Kinesin-13b constructs in which motor activity (Kinesin-13b ${ }^{\text {RIG }}$-Cerulean) (Dawson et al., 2007),

168 conserved MT depolymerisation motifs (Kinesin-13b ${ }^{\text {KVD/KEC }}$-Cerulean) (Shipley et al., 2004), and a

169 conserved MT binding domain (Kinesin-13b ${ }^{\text {Loop12 }}$-Cerulean) (Soppina and Verhey, 2014) were

170 compromised could not restore the retrograde nuclear movement (Figure 3D). Overall, these results

171 suggest that Kinesin-13s contribute to nuclear movement redundantly in a motor-dependent manner.

172 The severe retrograde nuclear/spindle movement during prophase likely resulted in cross cell wall

173 positioning defects in the Kinesin-13 KO moss. Indeed, analysis of subapical and apical cell length at

174 anaphase onset found that subapical cell length was reduced in the Kinesin-13 KO moss (Figure 3E, F).

175 This correlates with reduction in non-apical cell length of early stage moss colonies, and suggests that

176 moss Kinesin-13 has a role in cell length maintenance.

177 Consistent with the retrograde nuclear/spindle movement, high-resolution time-lapse imaging

178 showed that Kinesin-13 KO moss also has a disparity of the nucleus-surrounding MT array during

179 prophase (Figure 4A, Movie 1). In the control, shortly before NEBD, MTs associated asymmetrically to

180 the nucleus, with more MTs gathering on the apical side (Doonan et al., 1985; Nakaoka et al., 2012). In

181 contrast, this apically directed MT asymmetry was altered in the KO line, with the GFP-tubulin

182 intensity ratio of apical to basal hemispheres of the nucleus decreasing from $\sim 1.2$ in the control to $\sim 1.0$

183 (Figure 4B, C), suggesting that Kinesin-13s are important for MT organisation during prophase.

184 Upon NEBD, MTs assemble into a bipolar spindle. However, spindle assembly required more

185 time than control cells as anaphase onset was delayed, with the majority of the delay due to slow spindle

186 MT organisation as prometaphase was delayed but metaphase was unaffected (Figure 4D). Despite the

187 drastic nuclear movements and mitotic delay, MTs reorganised into the phragmoplast, which is the MT-

188 based machinery required for cell plate formation, and cytokinesis was completed in 15 out of 15 cells,

189 indicating that Kinesin-13s are dispensable in the later stages of cell division.

190 Unexpected from previous studies in animals and the predicted MT depolymerisation activity of

191 Kinesin-13, the metaphase spindle was shorter, rather than longer in the KO cells (Figure 4E). In animal

192 cells, MT depolymerisation at the spindle pole by Kinesin-13 is important for poleward flux of spindle

193 MTs, where tubulin is flowed from the spindle equator to the pole regions through the continuous 
194 addition and removal of tubulin heterodimers at the plus- and minus-ends, respectively (Rogers et al.,

195

196

197

198

199

200

201

202

203

204

205

206

207

208

209

210

211

212

213

214

215

216

217

218

219

220

221

222

223

224

225

226

227

228

2005). To investigate if Kinesin-13 depletion affects poleward MT flux in moss, GFP-tubulin at the equator of the mitotic spindle was bleached, and the movement of the photobleached strip was monitored. Surprisingly, the strip migrated towards the poles as in control cells, indicating that MT poleward flux took place in spite of complete Kinesin-13s depletion (Figure 4F, G, Movie 2). Thus, Kinesin-13 contributes to mitosis in an unconventional manner in moss.

\section{Kinesin-13 regulates straight growth of the protonema filament by controlling the position of MT focal points}

To study the colony growth defect of the Kinesin-13 KO line in detail, long-term time-lapse imaging of protonema filament growth was performed. Protonema filaments were found to be wavy with the protonema cell tip periodically changing growth direction in the Kinesin-13 KO line (Figure 5A, Movie 3). The Kinesin-13 KO line was shown to be wavier with a bend frequency of $0.024 \pm 0.002 \mu \mathrm{m}^{-1}$ (mean $\pm \mathrm{SEM} ; \mathrm{N}=26$ ) compared to the control $\left(0.006 \pm 0.001 \mu \mathrm{m}^{-1}\right.$, mean $\pm \mathrm{SEM} ; \mathrm{N}=28$ ) (Figure 5B). Interestingly, the Kinesin-13ac double KO line showed a milder wavy phenotype, while the single and Kinesin-13ab double KO lines did not (Supplemental Figure 3A). Additionally, ectopic expression of full-length Kinesin-13b rescued the waviness phenotype (Figure 5B, Supplemental Figure 3B). Thus, Kinesin-13s are required for straight tip-growth.

Directionality of protonema tip-growth in moss has been stipulated to be dependent on MTs (Doonan et al., 1988). At the apex of the protonema tip cell, plus-ends of MTs converge into a focus known as the MT foci (Hiwatashi et al., 2014). This occupies about the same place as the focal point of the actin filament cloud in a mutually dependent manner (Wu and Bezanilla, 2018; Yamada and Goshima, 2018). Tip-growth defects including abnormal tip branching, retarded growth, and isotropic growth are the phenotypes observed amongst transgenic mutants for regulators of cytoskeletal dynamics where its organisation at the tip is impaired (actin related proteins, myo8, KINID kinesin, KCH kinesin (Rounds and Bezanilla, 2013; Hiwatashi et al., 2014; Wu and Bezanilla, 2018; Yamada and Goshima, 2018)). As such, it is possible that Kinesin-13 depletion may result in defective MT organisation at the cell tip, causing abnormal wavy protonema growth. MT foci behaviour in the Kinesin-13 KO line was investigated with spinning disc confocal microscopy where the MT foci of the Kinesin-13 KO moss was unstable and fluctuated frequently (Figure 5C, D, Movie 4). Interestingly, in 19 of 20 bending events observed, the displacement of the MT foci occurred prior to cell bending, indicating that the MT foci dictated protonema growth direction (Supplemental Figure 4). These results suggest that Kinesin-13s regulate anisotropic growth of protonema filaments by positional maintenance of the MT foci at the cell tip. 


\section{Kinesin-13 is an interphase MT plus-end tracking protein}

230 To investigate Kinesin-13's localisation during interphase, endogenously tagged Kinesin-13-Citrine lines (Miki et al., 2014) was observed with spinning disc confocal microscopy. Consistent with the depletion data, Kinesin-13s localised to the MT foci (Figure 6A and Supplemental Figure 2B). To address if Kinesin-13 also associates with individual MTs in the endoplasm, we utilised oblique illumination fluorescence microscopy that enables observation of single MTs near the cell cortex with reduced effect of chloroplast autofluorescence (Jonsson et al., 2015; Nakaoka et al., 2015). In the interphase MT array, Kinesin-13s accumulated at the ends of growing MTs and disappeared from ends when MTs switched to the shrink phase (Figure 6B, C, Supplemental Figure 2C, Movie 5). Since MT minus-ends are stabilised and exhibit little to no dynamicity in this cell type (Leong et al., 2018), we concluded that Kinesin-13 localises to the plus-ends of growing MTs. The plus-end tracking behaviour is reminiscent of human KIF2C/MCAK and Drosophila KLP10A, which are recruited by EB1 protein to growing plus-ends (Mennella et al., 2005; Lee et al., 2008).

MT shrink rate and rescue frequency increase while MT growth rate and catastrophe frequency reduce upon Kinesin-13 depletion

Since Kinesin-13s tracked growing MT plus-ends, the effect of Kinesin-13 deletion on MT plus-end dynamics during interphase was analysed using time-lapse oblique illumination imaging of GFPtubulin. MT shrink rate increased upon Kinesin-13 depletion, from $0.25 \pm 0.01 \mu \mathrm{m} / \mathrm{s}$ (mean $\pm \mathrm{SEM} ; 5$ MTs per cell analysed, $\mathrm{N}=25$ cells) in the control to $0.43 \pm 0.02 \mu \mathrm{m} / \mathrm{s}$ (mean $\pm \mathrm{SEM} ; 5 \mathrm{MTs}$ per cell analysed, $\mathrm{N}=25$ cells) in the $\mathrm{KO}$ line (Figure $6 \mathrm{D}$ ). Catastrophe frequency reduced from $9.3 \pm 1.2 \times 10^{-}$ $3 / \mathrm{s}($ mean $\pm \mathrm{SEM} ; \mathrm{N}=33)$ in the control to $2.2 \pm 0.5 \times 10^{-3} / \mathrm{s}($ mean $\pm \mathrm{SEM} ; \mathrm{N}=28)$ in the $\mathrm{KO}$ line (Figure 6E), while rescue frequency increased from $14 \pm 3 \times 10^{-3} / \mathrm{s}($ mean $\pm \mathrm{SEM} ; \mathrm{N}=25)$ in the control to $25 \pm 6 \times 10^{-3} / \mathrm{s}$ (mean $\pm \mathrm{SEM} ; \mathrm{N}=23$ ) in the $\mathrm{KO}$ line (Figure $6 \mathrm{~F}$ ). To analyse MT growth rate, Kinesin-13 KO moss expressing EB1-Citrine (Supplemental Figure 1C), a tracker of growing MT plusends, was imaged with oblique illumination fluorescence microscopy. MT growth rate based on EB1Citrine comet movement reduced from $0.147 \pm 0.013 \mu \mathrm{m} / \mathrm{s}$ (mean $\pm \mathrm{SEM} ; 10$ MTs per cell analysed, $\mathrm{N}$ $=5$ cells) in the control to $0.093 \pm 0.003 \mu \mathrm{m} / \mathrm{s}$ (mean \pm SEM; 10 MTs per cell analysed, $\mathrm{N}=5$ cells) in the $\mathrm{KO}$ lines (Figure 6G). The results suggest that Kinesin-13 plays a role in regulating MT dynamics in the interphase MT network.

\section{Altered MT dynamics parameters may underlie MT length phenotypes in Kinesin-13 KO}

261 Depletion of MT depolymerases or catastrophe-promoting factors causes cytoplasmic MT lengthening

262 and spindle expansion (Howard and Hyman, 2007; Goshima and Scholey, 2010). For example, in

263 fission yeast cells lacking catastrophe-promoting factors, cytoplasmic MTs are more frequently 
264 polymerised beyond the limits of the cell, resulting in MT bending and curling (West et al., 2001).

265 However, shorter metaphase spindle formation (Figure 4E) and the observation that the MT foci often is unable to reach the apex of the cell tip in Kinesin-13 KO lines (Supplemental Figure 5, Movie 4) appear to be contradictory to this general rule. We reasoned that a decrease in MT growth rate and increase in shrink rate might be limiting for overall MT length, despite significant reduction in catastrophe frequency. To evaluate this idea, we built a probability model fixed by the parameters of MT growth rate, shrink rate, catastrophe frequency, and rescue frequency, and ran a simulation in which 4,000 MTs exhibit dynamic instability for $4 \mathrm{~min}$ (Figure $6 \mathrm{H}$, Table 1). With control parameters, a normal distribution was obtained where the $50 \%$ of MTs ranged from -12.4 to $23.4 \mu \mathrm{m}$ lengths, and the longest 1000 MTs ranged between 23.4 to $59.8 \mu \mathrm{m}$ lengths. In contrast, with MT dynamics parameters of Kinesin-13 KO cells, a narrower normal distribution was obtained, with 50\% of MTs having lengths of 11.5 to $22.6 \mu \mathrm{m}$ and the longest 1000 MTs ranged between 22.6 to $29.4 \mu \mathrm{m}$ lengths. Thus, the formation of shorter metaphase spindles and apex-displaced MT foci is a theoretically possible outcome, and actually a more likely outcome, associated with depletion of moss Kinesin-13 that affects both MT catastrophe frequency and growth/shrink rate.

\section{Kinesin-13 motor domain induces catastrophe in vitro}

To investigate the direct effect of moss Kinesin-13 on MT dynamics, recombinant Kinesin- $13 b^{\text {motor }}$ mGFP protein was expressed and purified from bacterial expression system (Figure 7A and Supplemental Figure 5A; full-length Kinesin-13 could not be obtained in either bacteria or insect culture cell expression system). The purified Kinesin- $13 b^{\text {motor }}$-mGFP protein was subjected to 'binding-release' experiments to confirm ATP hydrolysis activity: it bound to MTs in the presence of non-hydrolysable ATP analogue (AMPPNP) and dissociated from MTs upon ATP addition (Supplemental Figure 5B). The ATPase-active protein was added to GMPCPP-stabilised MTs, but did not show active MT depolymerisation like that of animal Kinesin-13 protein (Drosophila KLP10A) (Figure 7B) (Rogers et al., 2004; Moriwaki and Goshima, 2016). We considered the possibility of moss Kinesin-13 requiring a binding partner like MIDD1 for Arabidopsis Kinesin-13 (Oda and Fukuda, 2013). BLAST search showed that the moss does not have MIDD1 homologues, and so moss Kinesin-13 was tested for MT

292 depolymerisation activity in the presence of Arabidopsis MIDD1, but also did not depolymerise MTs

293 (Figure 7B). Overall, the purified Kinesin-13b ${ }^{\text {motor }}$-mGFP construct did not exhibit MT depolymerase activity under the current experimental condition..

The purified Kinesin- $13 \mathrm{~b}^{\text {motor }}$-mGFP was also subjected to an in vitro MT polymerisation assay at concentrations of $0,0.15,0.3,0.6,1.5 \mu \mathrm{M}$. While growth rate was somewhat reduced with higher

297 Kinesin-13b ${ }^{\text {motor }}$ concentration (Figure 7D), shrink rate and rescue frequency were not obviously

298 affected by Kinesin-13b ${ }^{\text {motor }}$-mGFP addition (Figure 7E, F). Interestingly, in the presence of Kinesin- 
$13 \mathrm{~b}^{\text {motor }}$-mGFP, catastrophe frequency was reproducibly increased (Figure $7 \mathrm{G}$ ). This result is consistent with in vivo data in which MT catastrophe frequency decreased in the Kinesin-13 KO line. In contrast, the recombinant protein did not reproduce the plus-end accumulation seen in vivo, indicating that truncated region and/or a separate factor may be required for plus-end recruitment.

\section{Chromosome segregation and cell division proceed normally in the absence of Kinesin-8}

Mitotic phenotype associated with Kinesin-13 deletion was fairly mild. We reasoned that another MT depolymerase instead might have a major role in MT depolymerisation in mitosis of protonema filaments, and thought to investigate Kinesin- 8 , which shows strong depolymerisation activity during mitosis of yeast (Hildebrandt and Hoyt, 2000; Unsworth et al., 2008). To study Kinesin-8 function in the moss, all three paralogous genes phylogenetically classed into the moss Kinesin- 8 subfamily (Kinesin-8Ia, -8Ib, -8II) (Shen et al., 2012; Miki et al., 2014) (Figure 1B) were knocked out (Supplemental Figure 1D). Moss colonies, gametophores, and rhizoids were normal in the Kinesin- 8 KO line (Figure 2A-C). High-resolution mitosis imaging did not show any defect in prophase MT organisation, spindle formation, chromosome alignment, anaphase chromosome segregation, and cytokinesis ( $9.1 \pm 0.2 \mathrm{~min}$ from NEBD to anaphase onset; $\mathrm{N}=10$ ) (Figure 4A, D, E). We concluded that Kinesin-8s are dispensable for mitotic cell division in moss protonema filaments.

\section{Kinesin-8 controls positioning of the MT foci for straight tip growth}

Interestingly, the Kinesin- $8 \mathrm{KO}$ line also had wavy protonema filaments with bends occurring at smaller magnitudes with a bend frequency of $0.022 \pm 0.005 \mu \mathrm{m}^{-1}$ (mean $\pm \mathrm{SEM}$; $\mathrm{N}=8$ ) (Figure 5A, B, Movie 3). Tracking of the MT foci at tip cells showed that it fluctuates more frequently in the Kinesin- $8 \mathrm{KO}$ line than in the control or Kinesin-13 KO (Figure 5C, D, Movie 4), consistent with its smaller magnitudes of bends.

\section{Kinesin-8II ${ }^{\text {motor }}$ glides MT but does not show a MT depolymerisation activity in vitro}

\section{To analyse intrinsic activity of moss Kinesin- 8 , the recombinant Kinesin-8II ${ }^{\text {motor }}$-GFP protein was} expressed and purified from bacterial expression system (Figure 8A, Supplemental Figure 5C) and was subjected to a MT depolymerisation assay. $200 \mathrm{nM}$ Kinesin-8II ${ }^{\text {motor }}$-GFP was added to GMPCPPstabilised MTs but could not depolymerise them, while 200 nM Saccharomyces cerevisiae Kinesin8/Kip3 could depolymerise the MTs (Figure 8B). Kinesin-8II ${ }^{\text {motor }}$-GFP was then tested for MT gliding activity. Protein immobilised on silanised cover glass showed ability to glide GMPCPP-stabilised MTs in an ATP-dependent manner, but also could not depolymerise those MTs (Figure 8C, D). 


\section{Discussion}

336 The KO lines generated in this study showed some characteristic phenotypes unreported in previous

337 plant kinesin mutants, such as wavy cell growth accompanying MT foci positional fluctuation (Kinesin-

338 13, Kinesin-8) and prophase MT disorganisation (Kinesin-13). Intriguingly, several processes driven by

339 these motors in many animal and yeast species were normal in their absence in moss, such as spindle

340 MT flux and chromosome segregation. Moreover, the hallmark activity of these kinesins, MT

341 depolymerisation, was not detected in vitro. Overall, this study provides a comprehensive view on the

342 roles of Kinesin-13 and -8 in a single plant species. Furthermore, our results reinforce the emerging

343 view that the kinesin superfamily is well conserved in plants but have diverged in their function

344 (Gicking et al., 2018; Nebenfuhr and Dixit, 2018).

\section{Are plant Kinesin-13 and -8 MT depolymerases?}

347 Kinesin-13 is a well-known MT depolymerase in animals. Arabidopsis and rice Kinesin-13s have also 348 been shown to depolymerise stabilised MTs (Oda and Fukuda, 2013; Deng et al., 2015). However, 349 moss Kinesin-13 only exhibited catastrophe-inducing activity in vitro and could not depolymerise 350 GMPCPP-stabilised MTs. This in vitro result is consistent with the reduced catastrophe frequency seen 351 with interphase MTs in the Kinesin-13 KO moss. Nevertheless, 'negative' results obtained in vitro is not 352 necessarily conclusive: inappropriate expression systems or unsuitable biochemical environments could 353 prevent full activity of the protein. In this study, a motor-only construct was used due to technical 354 constraints. Thus, it is possible that other domain(s) on the Kinesin-13 protein is required for MT 355 depolymerisation activity. One such element may be the coiled coil, which in animal Kinesin-13 356 dimerises the protein and increases MT depolymerisation activity (Hertzer et al., 2006). However, the 357 coiled coil region required for dimerisation is located immediately upstream/downstream of the motor 358 domain in animal Kinesin-13 (Maney et al., 2001), but is located further down the C-terminus in moss 359 Kinesin-13 (Figure 1A); it is unclear if dimerisation of moss Kinesin-13 could enhance the activity in a

360 similar manner to animal homologues. Furthermore, animal Kinesin-13 monomers are capable of 361 depolymerising MTs in vitro (Maney et al., 2001; Hertzer et al., 2006). It is also worth noting that moss

362 and also Arabidopsis Kinesin-13s lack the 'neck' domain that is important for strong MT

363 depolymerisation activity in animals (Ovechkina et al., 2002); based on this feature, it was indeed

364 originally speculated that plant Kinesin-13 might not have MT depolymerising activity (Lu et al., 2005).

365 Thus, although it is not ruled out that moss Kinesin-13 has a MT depolymerising activity, possibly with

366 the aid of a specific binding partner, it is enticing to say that it has diverged structurally and functionally

367 from animal Kinesin-13. 
In cells, there is even less evidence to support Kinesin-13 as a MT depolymerase. Upon Kinesin-13 $\mathrm{KO}$, interphase MTs show reduced MT growth rate and increased shrink rate. Such results instead point to Kinesin-13 being a MT growth promoter. However, MT growth promoting activity was not observed in vitro. This may be due to the use of the motor-only construct with which we could not recapitulate the plus-end enrichment of Kinesin-13. Alternatively, considering the decrease and increase in catastrophe and rescue frequency of interphase MTs, it is possible the Kinesin-13 regulates growth and shrink rate indirectly via tubulin cycling: reduced catastrophe would result in reduced availability of tubulin in the free tubulin pool, which might affect MT growth and shrink rates, as was proposed in the studies of Arabidopsis ARK proteins (Eng and Wasteneys, 2014) and more recently with plant-specific MT nucleator MACET4 (Schmidt and Smertenko, 2019).

Similar to Kinesin-13, we could not observe MT depolymerisation of the Kinesin-8 motor in our assay, which differs from human and yeast Kinesin- 8 . This might be due to our use of truncated construct ( $\sim 440$ a.a.) as we failed to purify the longer construct ( $\sim 640$ a.a.). However, we recently found that Drosophila Kinesin-8 (full-length) shows plus-end directed motility and induces MT catastrophe at the plus end, but is not able to depolymerise stable MTs in vitro (Edzuka and Goshima, 2019). Similar activities might be endowed to moss Kinesin-8.

\section{Kinesin-13 and -8 for mitosis}

386 We could not detect any phenotypes in Kinesin- $8 \mathrm{KO}$ lines during mitotic cell division, such as chromosome alignment and mitotic delay, which are common phenotypes observed in yeast and animal cells, suggesting that Kinesin- 8 has lost mitotic functions in moss. In contrast, some but not all known mitotic functions of Kinesin-13 (Walczak et al., 2013) were observed in moss. In animal mitosis, centrosomal MTs (astral MTs) are overly developed during prophase in the absence of Kinesin-13 (Goshima and Vale, 2003; Rogers et al., 2004). Similarly, disorganised MTs were observed around the nucleus, despite the loss of centrosomes in moss (and all other land plants). Nucleus surrounding MTs may act as MTOCs equivalent to animal centrosomes. During prometaphase, kinetochore-MT attachment appears to be less efficient, since prometaphase duration was slightly prolonged; whether this was due to overall MT dynamics change or the lack of error correction, like the case of

396 KIF2C/MCAK depletion in animal cells, remains elusive. Spindle monopolarisation that was observed 397 in centrosome-containing animal cells (Goshima and Vale, 2003) was not detected. At metaphase,

398 Kinesin-13 in animal cells acts as a MT depolymerase at the pole, driving MT poleward flux and

399 halting spindle extension. Surprisingly, we could not obtain data that moss Kinesin-13 plays such a role:

400 Kinesin-13 does not localised at the spindle pole, MT flux was detected in the Kinesin-13 KO line, and

401 the spindle was shorter, rather than longer, in the complete absence of Kinesin-13. MT dynamics is a

402 major contributor to spindle length regulation in animal somatic cells (Goshima and Scholey, 2010); 
403 therefore, shortening might be due to the reduced MT growth rate observed in the endoplasm,

404 consistent with Kinesin-13 localising at spindle equator where MT plus-ends are enriched.

405 Chromosome segregation during anaphase A was normal, further supporting the notion that Kinesin-13

406 does not act as a MT depolymerase at the pole. These data indicate that the moss mitotic spindle

407 possesses a mechanism to drive spindle MT poleward flux independent of Kinesin-13.

408

409 Kinesin-13 and -8 for tip growth

410 The most prominent phenotype observed both in the Kinesin- 13 and $-8 \mathrm{KO}$ lines was the tip-growth

411 defect. Recent studies suggest the importance of the MT converging centre, the MT foci, in protonema

412 tip-growth in moss, where F-actin, which is absolutely essential for tip-growth, is concentrated near the

413 MT foci. In several mutants of MT-associated motors in which tip grows more slowly, the MT foci is

414 not persistently formed (Hiwatashi et al., 2014; Wu and Bezanilla, 2018; Yamada and Goshima, 2018).

415 These transient MT foci produced bursts of MT concentration at random locations along the tip region

416 of the apical cell, causing the bending of the protonema filament at abrupt angles (Hiwatashi et al.,

417 2014). Such phenotypes are similar to tip-growth defects seen when moss is treated with MT disruptive

418 drugs (Doonan et al., 1988). Different from those mutants, we persistently observed a single MT focus

419 in the Kinesin- 13 or -8 KO. However, their positions were unstable, exhibiting the waviness of rather

420 regular amplitude and frequencies. This suggests that Kinesin- 13 and -8 play a role in MT foci

421 positional guidance, rather than MT foci formation/maintenance, which ensures straight growth of the

422 protonema filament. While straight tip-growth with limited MT foci fluctuations would allow fastest

423 propagation of moss, wavy growth would be an advantageous mechanism to facilitate innovative

424 exploration of the environment. Our study highlights the regulation of MT plus-end dynamics by MAPs

425 as an intracellular mechanism to modulate cell growth in response to environmental cues, reminiscent

426 of axon guidance in neurons (Sabry et al., 1991; Tanaka et al., 1995; Menon and Gupton, 2016).

427

\section{Materials \& Methods}

430 Molecular cloning and gene targeting experiments

431 All transgenic moss lines, plasmids, and primers used in this study are listed in Table S1, S2 and S3

432 respectively; all lines originated from the Physcomitrella patens Gransden 2004 strain. Moss culture,

433 transformation, and transgenic line selection were performed as previously described (Yamada et al.,

434 2016). In brief, moss cells were cultured on BCDAT or BCD media under $24 \mathrm{~h}$ light illumination, and

435 transformation was performed by the standard PEG-mediated method. 
KO moss generation Kinesin-13 KO (GPH0438) and Kinesin-8 KO (GPH0433) were generated in the moss strain expressing GFP-tubulin and histone-H2B-mRFP (Nakaoka et al., 2012) sequentially replacing the targeted genes with antibiotic resistance using homologous recombination (HR). To do this, $1 \mathrm{~kb}$ of genomic DNA sequences upstream/downstream of start/stop codons of the target genes were cloned around an antibiotic resistance cassette, and then transformed into the moss. To knock out Kinesin-13 genes in the moss expressing EB1-Citrine and mCherry-tubulin (Kosetsu et al., 2013), Kinesin-13b was first removed by antibiotic resistance mediated HR as described before. For Kinesin$13 a$ and $-13 c$, CRISPR mediated gene removal was utilised. 20 bp guide RNAs (gRNAs) targeting the start and end of the gene were designed using CRISPOR (http://crispor.tefor.net) (Figure S1A). gRNAs were then integrated into a BsaI site of a vector carrying U6 promoter and RNA scaffold (pCasGuide/pUC18) (Lopez-Obando et al., 2016; Collonnier et al., 2017), then the CRISPR cassettes were cloned into a vector carrying nourseothricin resistance (pSY034) with InFusion to assemble multiple gRNA cassettes into a plasmid (pSY062) following methods previously described (Leong et al., 2018). Equal amounts of this circular multicassette plasmid and Streptococcus pyogenes Cas 9 expression vector (pGenius, (Collonnier et al., 2017)) were transformed into the Kinesin-13b KO/EB1Citrine/mCherry-tubulin background. Confirmation of Kinesin-13 and Kinesin- $8 \mathrm{KO}$ lines (Figure S1B-D) were carried out by PCR as previously described (Yamada et al., 2016; Leong et al., 2018).

Endogenous C-terminal Citrine tagging C-terminal endogenous Kinesin-13 and -8 Citrine tagging lines from (Miki et al., 2014) were used. In these lines, Kinesin-13 and -8 were tagged endogenously with Citrine at the $\mathrm{C}$-terminal via $\mathrm{HR}$ where $1 \mathrm{~kb} \mathrm{C}$-terminal sequence and the downstream sequence of stop codon of the target gene flanking an antibiotic resistance cassette was used as the HR template.

459 Confirmation of this line was by PCR using primers designed to target the $\mathrm{C}$-terminal region and

460 outside the 3'UTR of the target gene. To make rescue plasmids, Kinesin-13 sequence was cloned from 461 a cDNA library and ligated into the pENTR/D-TOPO vector. The Kinesin-13 mutant plasmids 462 (Kinesin-13b ${ }^{\mathrm{RIG}}$-Cerulean, Kinesin-13b ${ }^{\mathrm{KVD} / \mathrm{KEC}}-$ Cerulean, Kinesin-13b ${ }^{\text {Loop12}}$-Cerulean) were generated

463 by mutagenesis with the full-length Kinesin- 13 plasmid and primers listed in Table S2, S3. The cloned

464 Kinesin-13 sequences were ligated into pMN603 vector by a Gateway LR reaction, which contains

465 EF1 $\alpha$ promoter, Cerulean gene, nourseothricin-resistance cassette, PTA1 sequences designated for

466 homologous recombination mediated integration (Miki et al., 2016; Yoshida et al., 2019).

\section{Imaging sample preparation}

469 Agar pad sample Moss samples used in time-lapse imaging were prepared either in 6-well glass

470 bottomed plates or $35 \mathrm{~mm}$ glass bottomed dishes as previously described (Yamada et al., 2016). Briefly, 471 protonema cells were plated onto glasses coated with BCD agar medium and culture for 4 to $6 \mathrm{~d}$. 
Microdevice sample Samples used for oblique illumination fluorescence microscopy were prepared in BCD liquid medium in $15 \mu \mathrm{m}$ height PDMS microfluidic chambers mostly following previously described methods (Leong et al., 2018; Kozgunova and Goshima, 2019). Briefly, protonema cells were homogenised in BCD liquid media, filtered through a sheet of $50 \mu \mathrm{m}$ nylon-mesh, and injected into microfluidic chambers attached unto $24 \mathrm{~m}$ x $32 \mathrm{~mm}$ micro cover glass (Matsunami, No. 1-S) and cultured for 4 to 6 days.

Calcofluor stained sample 8-days-old moss colonies regenerated from single protoplasts were mounted $0.1 \mathrm{mg} / \mathrm{mL}$ calcofluor solution diluted with water and covered with a cover glass. The samples were then imaged with Nikon Eclipse TE2000-E inverted microscope

\section{Moss colony assay}

486 Protoplast regeneration assay was performed following the method described in (Vidali et al., 2007) and (Yamada et al., 2016) with some modifications. In brief, sonicated moss on cellophane-lined BCDAT plate was digested by $8 \%$ mannitol solution supplemented with $2 \%$ driselase. Generated protoplasts were washed three times with $8 \%$ mannitol solution, and $1.5 \times 10^{5} \mathrm{~mL}^{-1}$ cells were resuspended with $7 \mathrm{ml}$ of protoplast regeneration liquid. After overnight incubation under the dark condition, the protoplasts were centrifuged at $510 \mathrm{~g}$ for $2 \mathrm{~min}$ and resuspended in $4 \mathrm{ml} \mathrm{PRM}$ solution in which $\mathrm{CaCl}_{2}$ was added after autoclave. $0.5-1 \mathrm{ml}$ out of $4 \mathrm{ml}$ protoplast solution was spread on cellophane-lined PRM plate. Then, protoplasts were cultured for $4 \mathrm{~d}$ and transferred to BCDAT plate, followed by $4 \mathrm{~d}$ culture. The 8 -days-old moss colonies were observed with a stereomicroscope.

\section{Live in vivo imaging}

497 Spinning disc confocal microscopy using 100x 1.45-NA lens and ImagEM camera (Hamamatsu

498 Photonics) was performed with Nikon Ti inverted microscope as previously described (Yamada et al.,

499 2016). Z-series were taken using Nano-Z Series nanopositioner combined with a Nano-Drive controller

500 (Mad City Labs), where z-stack imaging was performed at $0.3 \mu \mathrm{m}$. Oblique illumination fluorescence

501 microscopy was carried out with a Nikon Ti microscope with a TIRF unit, a 100x 1.49-NA lens,

502 GEMINI split view (Hamamatsu Photonics), and EMCCD camera Evolve (Roper). Microscopes were

503 controlled by Micromanager or NIS-Elements (Nikon). Low magnification epifluorescence imaging

504 was carried out using Nikon Eclipse TE2000-E inverted microscope with 10x/0.3 LN1C Plain Fluo

505 lens and Zyla 5.5 sCMOS camera (Andor), controlled with IQ3 (Andor). Photobleaching experiments

506 were performed using an LSM780-DUO-NLO confocal microscopy system (Zeiss) using Plan- 
507 Apochromat 63x/1.40 Oil DIC lens controlled using Zen (Zeiss) with $489 \mathrm{nM}$ diode laser (time-lapse 508 imaging taken at $2 \mathrm{~mW}$ and bleaching at $100 \mathrm{~mW}$ ). Moss expressing GFP-tubulin (GPH0438\#30 for

509 Kinesin-13 KO and GFP-tubulin/histoneH2B-mRFP for control) were used for photobleaching

510 experiments where images were acquired every $3 \mathrm{~s}$. All imaging was performed at room temperature in

511 the dark. Moss colonies and gametophores were imaged with SMZ800N (Nikon) and ILCE-QX1

512 camera (SONY). The stereomicroscope system was controlled with PlayMemories software (SONY).

513

514 Computer simulations

515 Simulations were built in R (version 3.6.0)

516 (https://github.com/TomoyaEdzuka/MT dyanamics simulation). Parameters used in this simulation for

517 each condition (control or Kinesin-13 KO) are listed in Table 1. In this simulation, catastrophe and

518 rescue frequency parameters were used to determine the probability of individual steps (1 s) undergoing

519 a transition change or to continue a growth/shrink phase. At each phase transition (i.e.

520 catastrophe/rescue event) new growth/shrink rates were assigned following a log normal distribution of

521 the growth and shrink parameters. MT lengths were then simulated for 4,000 trials (i.e. 4,000 MTs) for

522240 steps (i.e. $4 \mathrm{~min})$.

523

\section{Protein purification}

525 The motor domain of Kinesin-13b, which is the most highly expressed protein of the three paralogous

526 Kinesin-13 genes, was cloned from moss cDNA and transgenically linked to monomeric GFP (mGFP)

527 and 6xHis at the C-terminus (plasmid pGG885, Table S2). Kinesin-13b ${ }^{\text {motor }}$-mGFP expression was

528 induced in SOLBL21 E. coli with $0.1 \mathrm{mM} \mathrm{IPTG}$ for $20 \mathrm{~h}$ at $18^{\circ} \mathrm{C}$. Harvested cells were lysed using the

529 Advanced Digital Sonifier D450 (Branson) in lysis buffer (50 mM Tris-HCl [pH 8.0], $100 \mathrm{mM} \mathrm{KCl,} 2$

$530 \mathrm{mM} \mathrm{MgCl}_{2}, 20 \mathrm{mM}$ imidazole, $0.1 \mathrm{mM} \mathrm{ATP}$ ) supplemented with $10 \mathrm{mM} \beta$-mercaptoethanol and

531 protease inhibitors (1 mM PMSF and peptide inhibitor cocktail:5 mg/mL Aprotinin, $5 \mathrm{mg} / \mathrm{mL}$

532 Chymostatin, $5 \mathrm{mg} / \mathrm{mL}$ Leupeptin, $5 \mathrm{mg} / \mathrm{mL}$ Pepstatin A). After rotation with nickel-NTA coated beads

533 for $2 \mathrm{~h}$ at $4{ }^{\circ} \mathrm{C}$, the proteins were eluted using $500 \mu \mathrm{L}$ elution buffer $(50 \mathrm{mM}$ Tris- $\mathrm{HCl}[\mathrm{pH} 8.0], 100$

$534 \mathrm{mM} \mathrm{KCl}, 2 \mathrm{mM} \mathrm{MgCl}_{2}, 300 \mathrm{mM}$ Imidazole, $0.1 \mathrm{mM} \mathrm{ATP}$ ). Elution was repeated 5 to 7 times. The

535 eluates were then further purified through an AMPPNP-ATP 'binding-release' experiment. Eluates

536 were first bound with $1 \mathrm{mM}$ AMPPNP to $76.5 \mu \mathrm{M}$ of $1 \mathrm{mM}$ GMPCPP-stabilised MTs, and sedimented

537 through an $80 \%$ glycerol cushion. Finally, the proteins were released from the pellet with $10 \mathrm{mM} \mathrm{ATP}$.

538 The motor domain and nearby coiled-coil domain (residues 200-639) of Kinesin-8II was cloned from

539 moss cDNA and transgenically joined to GFP and 6xHis tag at the C-terminus (pTM266, Table S2),

540 and introduced into a pET-23 E. coli expression vector. The recombinant protein was purified from

541 SOLBL21 E. coli induced with $0.2 \mathrm{mM} \mathrm{IPTG}$ for $20 \mathrm{~h}$ at $18^{\circ} \mathrm{C}$. Harvested cells were lysed using the 

mercaptothanol and protease inhibitors ( $0.5 \mathrm{mM}$ PMSF and peptide inhibitor cocktails). After rotation with nickel-NTA coated beads $\left(0.5 \mathrm{~mL}\right.$ bed volume) for $2 \mathrm{~h}$ at $4{ }^{\circ} \mathrm{C}$, proteins were eluted with $500 \mu \mathrm{L}$ elution buffer (25 mM MOPS [pH 7.0], $250 \mathrm{mM} \mathrm{KCl,} 2 \mathrm{mM} \mathrm{MgCl}_{2}, 400 \mathrm{mM}$ imidazole, $5 \%$ sucrose, $1 \mathrm{mM}$ ATP, $5 \mathrm{mM} \beta$-mercaptoethanol). Elution was repeated 5 to 7 times. Eluates were used immediately. For the in vitro MT depolymerisation assay, the buffer for the elute was exchanged to $1 \mathrm{x}$ Standard Assay Buffer (SAB: 25 mM MOPS [pH 7.0], 75 mM KCl, 2 mM MgCl 2,1 mM EGTA) supplemented with $1 \mathrm{mM}$ ATP to remove imidazole using PD-25 column (GE Healthcare). Drosophila KLP10A (plasmid pGG885) was purified referencing (Moriwaki and Goshima, 2016), and was purified with the same protocol as Kinesin- $13 b^{\text {motor }}$-mGFP. Instead of the 'binding-release' experiment, elutes of KLP10A were subjected to buffer exchange to $1 \mathrm{xMRB} 80$ with $75 \mathrm{mM} \mathrm{KCl}$ and $0.1 \mathrm{mM}$ ATP using a PD-25 column (GE Healthcare). AtMIDD1 was purified following (Oda and Fukuda, 2013), with some modifications. Briefly, GST-AtMIDD1 expression was induced in SOLBL21 E. coli using $0.2 \mathrm{mM}$ IPTG, and cultured for $20 \mathrm{~h}$ at $18^{\circ} \mathrm{C}$. Harvested cells were lysed using the Advanced Digital Sonifier D450 (Branson) in lysis buffer (10 mM HEPES [pH 7.4], 1 mM EGTA, 1 mM MgCl 2,150 $\mathrm{mM} \mathrm{KCl}$ ) supplemented with $1 \mathrm{mM}$ DTT and protease inhibitors $(0.5 \mathrm{mM}$ PMSF and peptide inhibitor cocktails). After rotation with Glutathione Sepharose 4B beads (GE Healthcare, $0.5 \mathrm{~mL}$ bed volume) for $2 \mathrm{~h}$ at $4{ }^{\circ} \mathrm{C}$, proteins were eluted with $500 \mu$ L elution buffer (100 mM HEPES [pH 7.4], $100 \mathrm{mM}$ $\mathrm{KCl}, 30 \mathrm{mM}$ reduced glutathione). Elution was repeated 5 to 7 times. Buffer was then exchanged using a PD-10 column (GE Healthcare). Budding yeast Kip3 was purified following Kip3 purification (Gupta et al., 2006) and Drosophila KLP67A purification (Edzuka and Goshima, 2019). In brief, ScKip3sfGFP-6xHis (pED273) was expressed in Sf21 moth cells at $27^{\circ} \mathrm{C}$ for $72 \mathrm{~h}$. Cells were lysed with 1\% Triton X-100 in lysis buffer (50 mM MOPS [pH 7.0], $250 \mathrm{mM} \mathrm{NaCl}, 2 \mathrm{mM} \mathrm{MgCl} 2,1 \mathrm{mM}$ EGTA, 20 $\mathrm{mM}$ imidazole, $0.1 \mathrm{mM}$ ATP) supplemented with $2 \mathrm{mM} \beta$-mercaptothanol and protease inhibitors $(0.5$ $\mathrm{mM}$ PMSF and peptide inhibitor cocktails) for $30 \mathrm{~min}$ at $25^{\circ} \mathrm{C}$. After rotation with nickel-NTA coated beads ( $0.5 \mathrm{~mL}$ bed volume) for $2 \mathrm{~h}$ at $4{ }^{\circ} \mathrm{C}$, proteins were eluted with $500 \mu \mathrm{L}$ elution buffer $(25 \mathrm{mM}$ MOPS [pH 7.0], $250 \mathrm{mM} \mathrm{KCl,} 2 \mathrm{mM} \mathrm{MgCl}$, $400 \mathrm{mM}$ imidazole, $5 \%$ sucrose, $1 \mathrm{mM}$ ATP, $5 \mathrm{mM} \beta$ mercaptoethanol). Buffer was then exchanged to $1 \mathrm{xSAB}$ supplemented with $1 \mathrm{mM}$ ATP to remove imidazole using PD-25 column (GE Healthcare).

In vitro MT depolymerisation

574 The in vitro MT depolymerisation assay in (Moriwaki and Goshima, 2016) and (Gell et al., 2010) was

575 followed with some modifications. DmKLP10A, Kinesin-13b ${ }^{\text {motor }}$-mGFP, AtMIDD1, and AtMIDD1 576 and Kinesin-13b ${ }^{\text {motor }}$-mGFP were mixed with 30\% Alexa Fluor-568 labelled GMPCPP-MT seeds 
577 immobilised on silanised cover glass in assay buffer with (1x MRB80, $1 \mathrm{mM}$ ATP, $50 \mathrm{mM}$ glucose, 0.5

$578 \mu \mathrm{g} / \mu \mathrm{L} \kappa$-casein, $0.1 \%$ methylcellulose) supplemented with an oxygen scavenger system. Similarly,

579 Kinesin-8II ${ }^{\text {motor }}$-GFP and ScKip3 were also introduced to immobilised GMPCPP-MT seeds, but in a

580 different assay buffer ( $1 \mathrm{xSAB}, 0.1 \%$ methylcellulose, $50 \mathrm{mM}$ glucose, $0.5 \mu \mathrm{g} / \mu \mathrm{L} \kappa$-casein, $1 \mathrm{mM}$ ATP,

$58175 \mathrm{mM} \mathrm{KCl}$, supplemented with oxygen scavenger system). Proteins were used at $200 \mathrm{nM}$

582 concentrations, except AtMIDD1 which was used at $100 \mathrm{nM}$ following (Oda and Fukuda, 2013). TIRF

583 imaging was taken every $3 \mathrm{~s}$ for $10 \mathrm{~min}$ at $25^{\circ} \mathrm{C}$.

In vitro MT polymerisation assay

586 We largely followed methods previously described (Li et al., 2012; Moriwaki and Goshima, 2016;

587 Leong et al., 2018) for the MT polymerisation assay. MT growth was initiated by flowing $20 \mu \mathrm{M}$

588 porcine brain tubulin (containing 10\% Alexa Fluor 647-labelled tubulin) and 0, 0.15, 0.3, 0.6, and 1.5

$589 \mu \mathrm{M}$ purified Kinesin-13b ${ }^{\text {motor }}$-mGFP in assay buffer (1x MRB80, $75 \mathrm{mM} \mathrm{KCl,} 1 \mathrm{mM}$ ATP, $50 \mathrm{nM}$

590 glucose, $1 \mathrm{mM} \mathrm{GTP}, 0.8 \mu \mathrm{g} / \mu \mathrm{L} \kappa$-casein, $0.1 \%$ methylcellulose) supplemented with an oxygen

591 scavenger system. TIRF imaging of Alexa Fluor-568 labelled GMPCPP-MT seeds and Alexa Fluor-

592647 labelled free tubulin was taken every $3 \mathrm{~s}$ for $10 \mathrm{~min}$ at $25^{\circ} \mathrm{C}$. Kymographs were drawn for 25

593 trackable dynamic MTs, and were analysed for catastrophe events and rescue events. Catastrophe

594 frequency was then defined by the number of catastrophe events per growth time (min), whereas rescue

595 frequency was defined by the number of rescue event per shrink time ( $\mathrm{min}$ ). Growth and shrink rates

596 were taken from the corresponding slopes from the same kymographs. Three independent experiments,

597 each with a different batch of purified proteins were performed.

\section{In vitro MT gliding assay}

600 For the gliding assay with purified Kinesin-8II ${ }^{\text {motor }}$-GFP, methods described in (Miki et al., 2015) were

601 referenced. Briefly, $10 \mu \mathrm{L}$ of the freshly purified recombinant protein was introduced into the flow

602 chamber and incubated at room temperature for $2 \mathrm{~min}$ in the dark, then washed with $20 \mu \mathrm{L} 1 \mathrm{x}$ Standard

603 Assay Buffer (SAB: $25 \mathrm{mM}$ MOPS [pH 7.0], $75 \mathrm{mM} \mathrm{KCl}, 2 \mathrm{mM} \mathrm{MgCl} 2,1 \mathrm{mM}$ EGTA). Then $10 \mu \mathrm{L}$

604 reaction mix (1xSAB, $0.1 \%$ methylcellulose, $50 \mathrm{mM}$ glucose, $0.5 \mu \mathrm{g} / \mu \mathrm{L}$ к-casein, $50 \mathrm{mM}$ GMPCPP-

605 MT seeds, $75 \mathrm{mM} \mathrm{KCl}$, supplemented with oxygen scavenger system and varying concentrations of

606 ATP) was introduced into the flow chamber, and it was sealed with candle wax. TIRF imaging of

607 Alexa Fluor-647 labelled GMPCPP-MT seeds in in vitro MT gliding assays with Kinesin-8II ${ }^{\text {motor }}$-GFP

608 at varying ATP concentrations addition was taken every $3 \mathrm{~s}$ for $10 \mathrm{~min}$ at $23-25^{\circ} \mathrm{C}$. Kymographs were

609 drawn for 30 50 trackable dynamic MTs per sample, and the slopes of the kymographs were taken as

610 gliding velocity.

611 


\section{Data analysis}

613 Moss colony growth rate GPH0438\#30 (Kinesin-13 KO) and GPH0002\#5 (control) protoplasts were

614 made following (Yamada et al., 2016) with some modifications. In brief, moss was incubated with 2\%

615 driselase solution (in 8\% mannitol), washed thrice with $8 \%$ mannitol, incubated overnight in protoplast

616 liquid medium, and then plated in PRM/T medium on cellophane-lined PRM plates, cultured at $25^{\circ} \mathrm{C}$

617 under continuous light. On day 2, moss-lined cellophane was transferred to BCDAT plates. Around day

6187 when individual colonies were larger, they were picked and inoculated on BCDAT plates, and

619 cultured at $25^{\circ} \mathrm{C}$ under continuous light. On day 27-28, images of plates with grown colonies were

620 taken with the in-built camera of Xperia X Performance (23 MP Type 1/2.3' Exmor RS sensor, $24 \mathrm{~mm}$

621 equivalent lens with $\mathrm{f} / 2.0$ aperture). Images were analysed with FIJI, where images were first converted

622 to 8-bit, automatically thresholded, and binarised. Colonies were automatically outlined with the wand

623 tool and resulting area was obtained. Data in Figure 2B is pooled from three independent experiments.

Non-apical cell length Low magnification calcofluor stained images of moss colonies were used

626 to measure non-apical cell length (see Figure 2E cartoon), where only caulonema cells were

627 measured. To distinguish between caulonema and chloronema cells, protonema filaments were

628 first judged by sight in bright field images of the same colonies, in which chloroplast density was

629 used as an indicator of cell state (caulonema, chloroplast sparse; chloronema, chloroplast dense).

630

631 Branching distance, branch filament length, and branching angle Low magnification images of

632 8-days-old moss colonies regenerated from single protoplasts were used to analyse branching

633 pattern parameters. Branching parameters were manually measured as shown in cartoon Figure

$6342 \mathrm{E}$.

635

Nuclear movement velocity Samples from epifluorescence imaging of moss protonema filaments

637 undergoing mitosis were analysed. Kymographs were drawn on the filaments, and nuclear movement

638 velocity was obtained from the slopes of nuclear movement in these kymographs where positive and

639 negative values were assigned to apical and basal directions, respectively.

641 Subapical cell length Samples from epifluorescence imaging of moss protonema filaments undergoing

642 mitosis were analysed. Kymographs were drawn on the filaments, and the lengths from the middle of

643 the spindle at anaphase to the cell tip and to the previous cell plate was measured as apical and subapical

644 cell length, respectively (see Figure 3E cartoon). 
646 GFP-tubulin intensity around the nucleus Spinning disc confocal fluorescence time-lapse imaging of

647 GFP-tubulin and histoneH2B-mRFP moss taken every 1 min was used for analysis. Segmented line

648 built-in tool in FIJI was used to mark the hemispheric circumference around the nucleus on the apical

649 and basal side at 1 min before NEBD (see Figure 4B cartoon) and mean pixel intensity was measured.

650 Apical:basal GFP-intensity ratio was defined as the ratio of the mean pixel intensity of the apical

651 hemisphere over that of the basal hemisphere.

652

Mitotic duration Mitosis images taken every 1 min with spinning disc confocal microscope were used for analysis. Mitotic duration was defined as time from NEBD to anaphase onset, whereas prometaphase is the time from NEBD to chromosome alignment, and metaphase duration is the time from chromosome alignment to anaphase onset.

657

Spindle length Mitosis images taken every 1 min with spinning disc confocal microscope were used for analysis. The metaphase spindle (defined as $1 \mathrm{~min}$ before anaphase onset) was used to analyse spindle area. 4 points (the two limits of basal and apical pole widths) were marked and their (x,y) positions were obtained, where spindle length was obtained from the distance between the midpoints of the basal and apical pole widths.

663

Spindle MT flux rate Mitosis images were taken every $3 \mathrm{~s}$ with LSM780-DUO-NLO confocal microscope. Kinesin-13 KO (GPH0438\#30) and control (GFP-tubulin/histoneH2B-mRFP) mitosis

666 were used for analysis. Cells were bleached along the equator of the mitotic spindle shortly after NEBD 667 once the spindle shape was formed, before anaphase entry. 38-pixel width slices covering the length of 668 the spindle were cut out and arranged using the montage tool in FIJ for easy viewing of the movement of the bleached region, where their slopes were then taken as MT flux rate.

Protonema filament bend frequency Epifluorescence images of moss protonema filaments cultured on

672 BCDAT media were used for analysis in FIJI. Contrast was adjusted to make edges of protonema

673 filaments clearer. A blind test was performed to ascertain waviness threshold, where acute angles above

$67418^{\circ}$ were determined to be 'wavy'. Randomly chosen protonema filaments were analysed for all the

675 angles of bends along a length of protonema filament using the FIJI in-built angle tool. The number of

676 bends that were 'wavy' $\left(>18^{\circ}\right)$ were counted, and taken over the length measured as bend frequency.

677

678 MT foci trajectories The MT foci of Kinesin-13 KO, $-8 \mathrm{KO}$, and control moss expressing GFP-tubulin

679 were imaged at $60 \mathrm{x}$ magnification with z-series every $0.3 \mu \mathrm{m}$ for a range of $20 \mu \mathrm{m}$ every $3 \mathrm{~min}$ for $3 \mathrm{~h}$.

680 Maximum z-projection of the files were analysed using FIJI MOSAIC plug-in (Sbalzarini and 
681 Koumoutsakos, 2005) particle tracker 2D/3D (radius: 20, cut-off: 0.001, per/abs: 0.005, link range: 5,

682 displacement: 20, dynamics: Brownian) to automatically generate the MT foci trajectories. The linear

683 regression of the trajectories was rotated to horizontal and normalised to start at $(x, y)=(0,0)$ in order to

684 plot graphs in Figure 5D.

685

686 Interphase endoplasmic MT plus-end dynamics For plus-end shrink rate, catastrophe frequency, and

687 rescue frequency, oblique illumination time-lapse images taken every $3 \mathrm{~s}$ of the interphase endoplasmic

688 MT network of Kinesin-13 KO (GPH0438\#30) and control (GFP-tubulin/histoneH2B-mRFP) were

689 analysed. For MT shrink rate, kymographs were drawn on five randomly chosen MTs per cell (cell $\mathrm{N}=$

69025 ; total MT N = 125), and the slope was taken as shrink rate. To analyse catastrophe and rescue

691 frequencies, $\sim 5$ x $6 \mu \mathrm{m}$ area in a cell was randomly selected whereupon every traceable MT plus-end

692 was traced for a kymograph to count the number of catastrophe or rescue events over the observed

693 growth or shrink time respectively. For ease of tracking, areas with fewer MTs but were not near the

694 cell plate were preferred. Two independent experiments were performed and consistent. To determine

695 MT growth rate, Kinesin-13 KO moss expressing EB1-Citrine was used, where Citrine marks growing

696 MT plus-ends. Spinning disc time-lapse images taken every $3 \mathrm{~s}$ of the interphase endoplasmic MT array

697 in Kinesin-13 KO (GPH0577\#2, 11) and control (EB1-Citrine/mCherry-tubulin, GPH0379\#2) moss

698 were analysed. Kymographs were taken along the edge of the apical side of the tip cell of protonema

699 filaments. Slopes of EB1-Citrine comets in kymographs were measured and taken as growth rate.

Statistics Welch's two-sample t-test (two-sided) was used when samples were approximately normally distributed. Tukey multiple comparison test was used for Figure 5B. Significance with the following pvalues are indicated as follows: $*<0.05 ; * *:<0.01 ; * * *:<0.001 ; * * * *:<0.0001$.

\section{Accession numbers}

Physcomitrella patens Kinesin-13a, Pp3c1_27370; Kinesin-13b, Pp3c14_9830; Kinesin-13c,

Pp3c10_106980; Kinesin-8Ia, Pp3c1_32120; Kinesin-8Ib, Pp3c2_3070; Kinesin-8II, Pp3c21_9290.

\section{Author contributions}

710 MY and GG conceived project; SYL and MY designed and performed experiments; SYL, TE, and

711 MY analysed experimental data; TE performed computer simulation; SYL, GG, and MY wrote paper.

\section{Acknowledgements}

714 We would like to thank Yoshihisa Oda, Momoko Nishina and Tomohiro Miki for moss lines and

715 plasmids; Yoshikatsu Sato and Advanced Imaging Support (ABiS) platform (JP16H06280) for help of 
716 photobleaching experiments; Elena Kozgunova, and Rie Inaba for technical assistance, Mitsuyasu

717 Hasebe for reagents, and Shogo Takatani for discussions. This work was funded by JSPS KAKENHI

718 (17H06471 to G.G. and 19K23723 to M.Y.) and by JSPS and DFG under the Joint Research Projects-

719 LEAD with UKRI (to G.G.). The authors declare no competing interests.

720

\section{Figure legend}

722 Figure 1: Conservation of Kinesin-13 and Kinesin-8 in the moss Physcomitrella patens.

723 (A) Protein domains of Kinesin-13 (represented with Kinesin-13b) and Kinesin-8 (represented with

724 Kinesin-8II) of moss, compared against Drosophila melanogaster KLP10A/Kinesin-13 and budding

725 yeast Saccharomyces cerevisiae Kip3/Kinesin-8. Domains of Drosophila and budding yeast proteins

726 were referenced from UniProt, whereas moss protein domains were predicted using InterPro.

727 (B, C) Kinesin-13 and -8 phylogeny across the moss Physcomitrella patens, the Brassicaceae

728 Arabidopsis thaliana, the liverwort Marcantia polymorpha, the rice Oryza sativa subspecies Japonica,

729 the fruit fly Drosophila melanogaster, mammalians Mus muculus and Homo sapiens, and also for

730 Kinesin-8 in budding yeast Saccharomyces cerevisiae and fission yeast Schizosaccharomyces pombe.

731 After amino acid sequences were aligned with MAFFT, gapped regions were removed manually using

732 MacClade. The phylogenetic tree was constructed using neighbour-joining methods using the Molecular

733 Evolutionary Genetics Analysis (MEGA) software. Reliability was assessed with 1,000 bootstrapping

734 trials. Protein sequences are presented in supplemental dataset. Horizontal branch length is proportional

735 to the estimated evolutionary distance. Bar, 0.1 amino acid substitution per site.

736

737 Figure 2: Kinesin-13 and -8 KO mosses are morphologically normal, but Kinesin- 13 KO moss shows

738 retarded growth and reduced cell length.

739 (A, B) Colony size comparison between control (GFP-tubulin/histoneH2B-mRFP) and Kinesin-13 KO

740 (GPH0438\#30, left) or Kinesin-8 KO (GPH0433\#9, right) moss. Colonies were cultured from single

741 protoplasts for 27-28 days on BCDAT where at least two independent experiments each with at least 2

742 plates of colonies were performed. The average colony area for each line on each plate was obtained.

743 Actual areas were then divided by the average area of the control sample to get relative colony size. In

744 the Kinesin-13 KO experiment, KO moss had a relative size of $0.55 \pm 0.04$ (mean $\pm \mathrm{SEM} ; \mathrm{N}=7$ )

745 whereas control had a relative size of $1.00 \pm 0.12$ (mean $\pm \mathrm{SEM} ; \mathrm{N}=6)$. In the Kinesin- $8 \mathrm{KO}$

746 experiment, $\mathrm{KO}$ moss had a relative size of $1.01 \pm 0.05($ mean $\pm \mathrm{SEM} ; \mathrm{N}=8)$ whereas control had a

747 relative size of $1.00 \pm 0.08$ (mean $\pm \mathrm{SEM} ; \mathrm{N}=8$ ). Points represent individual colonies, results are from

748 one of at least two independent experiment. Bar, $5 \mathrm{~mm}$. 
749 (C) Gametophore and rhizoids of control (GFP-tubulin/histoneH2B-mRFP) and Kinesin-13 KO

750 (GPH0438\#6) or Kinesin-8 KO (GPH0433\#7) moss. Gametophores were isolated from colonies from

751 small colony subcultures cultured on BCDAT for 27-28 days. Bar, $1 \mathrm{~mm}$.

752 (D) Day-8 moss colonies cultured from protoplast of control (GFP-tubulin/histoneH2B-mRFP) and

753 Kinesin-13 KO (GPH0438\#30) under brightfield light (top) and with calcofluor staining (bottom).

754 Yellow dashes boxes, inset region; bars, $500 \mu \mathrm{m}$; inset bar, $50 \mu \mathrm{m}$.

755 (E) Cartoon depicting the measurements taken for non-apical cell length in (F) and branching phenotype

756 analysis in $(\mathrm{G})$.

757 (F) Non-apical cell lengths of caulonema filaments were measured using calcofluor stained colonies as in

758 (D, bottom) for control (GFP-tubulin/histoneH2B-mRFP) and Kinesin-13 KO (GPH0438\#30). Non-

759 apical cell length was reduced in Kinesin-13 KO moss to $79.9 \pm 5.5 \mu \mathrm{m}$ (mean $\pm \mathrm{SEM} ; \mathrm{N}=43$ ),

760 compared to control moss of $113.7 \pm 1.9 \mu \mathrm{m}$ (mean $\pm \mathrm{SEM} ; \mathrm{N}=132$ ). Points represent individual cells;

761 results are pooled from two independent experiments where two independent lines were analysed.

762 (G) Branching phenotype analysis of control (GFP-tubulin/histoneH2B-mRFP) and Kinesin-13 KO

763 (GPH0438\#30). In particular, branching distance of the first branch site to cell tip (top graph, leftmost

764 bars) was increased in Kinesin-13 KO moss to $338.4 \pm 12.9 \mu \mathrm{m}$ (mean $\pm \mathrm{SEM}$; $\mathrm{N}=55$ ), compared to

765 control moss of $293.1 \pm 8.8 \mu \mathrm{m}$ (mean $\pm \mathrm{SEM} ; \mathrm{N}=71$ ). Points represent individual filaments; results are

766 pooled from two independent experiments where two independent lines were analysed.

768 Figure 3: Kinesin-13s contribute to triple KO moss shows retrograde nuclear movement not seen in

769 single KOs, but manifests in to a lesser degree in the Kinesin-13ac double KO line.

770 (A) Snapshots of control (GFP-tubulin/histoneH2B-mRFP) and Kinesin-13 KO (GPH0438\#30) moss

771 during prophase nuclear/spindle movement. Kinesin-13 KO moss shows retrograde nuclear/spindle

772 movement. Apical side, right, positive value for analysis in (B) and (D); basal side, left, negative values

773 for analysis in (B) and (D); yellow dotted line, nucleus position at NEBD; bar, $50 \mu \mathrm{m}$; NEBD, 0 min.

774 (B) Nuclear movement velocity during prophase of control (GFP-tubulin/histoneH2B-mRFP; $0.68 \pm$

$7750.10 \mu \mathrm{m} / \mathrm{min}$, mean $\pm \mathrm{SEM} ; \mathrm{N}=8)$, Kinesin-13a single KO (GPH0411\#43; $0.85 \pm 0.10 \mu \mathrm{m} / \mathrm{min}$, mean

$776 \pm \mathrm{SEM} ; \mathrm{N}=8)$, Kinesin-13b single $\mathrm{KO}(\mathrm{GPH} 0412 \# 11 ; 0.43 \pm 0.03 \mu \mathrm{m} / \mathrm{min}$, mean $\pm \mathrm{SEM} ; \mathrm{N}=7$ ),

777 Kinesin-13ab double KO (GPH0419\#33; $0.62 \pm 0.04 \mu \mathrm{m} / \mathrm{min}$, mean $\pm \mathrm{SEM} ; \mathrm{N}=11)$, Kinesin-13ac

778 double KO (GPH0420\#125; $-0.03 \pm 0.13 \mu \mathrm{m} / \mathrm{min}$, mean $\pm \mathrm{SEM} ; \mathrm{N}=16$ ), and Kinesin-13abc triple KO

779 (GPH0438\#30; $-0.69 \pm 0.08 \mu \mathrm{m} / \mathrm{min}$, mean $\pm \mathrm{SEM} ; \mathrm{N}=11$ ). Kinesin-13abc triple KO shows a clear

780 retrograde nuclear movement, whereas Kinesin-13ac double KO shows intermediate retrograde nuclear

781 movement. Apically directed movement, positive values; basally directed movement, negative values. 
782 represent individual mitotic events. Results are from one of three independent experiments where two 783 independent lines were analysed.

784 (C) Protein domains of Kinesin-13b and mutant proteins for rescue experiments. Point mutations on

785 Kinesin-13b-Cerulean which was introduced under the EFl $\alpha$ promoter at the PTA1 site in the moss used 786 for rescue experiments are illustrated.

787 (D) Nuclear movement velocity during prophase of control (GFP-tubulin/histoneH2B-mRFP; $0.94 \pm$

$7880.10 \mu \mathrm{m} / \mathrm{min}$, mean $\pm \mathrm{SEM} ; \mathrm{N}=17)$, Kinesin-13abc triple $\mathrm{KO}(\mathrm{GPH} 0438 \# 30 ;-1.43 \pm 0.22 \mu \mathrm{m} / \mathrm{min}$,

789 mean \pm SEM; $N=29$ ), Cerulean/Kinesin-13abc triple KO (GPH0903\#1; $-0.99 \pm 0.25 \mu \mathrm{m} / \mathrm{min}$, mean \pm

790 SEM; N = 16), Kinesin-13b(FL)-Cerulean/Kinesin-13abc triple KO (GPH0899\#10; $1.04 \pm 0.09$

$791 \mu \mathrm{m} / \mathrm{min}$, mean $\pm \mathrm{SEM} ; \mathrm{N}=13)$, Kinesin-13b ${ }^{\text {RIG }}$ Cerulean/Kinesin-13abc triple KO (GPH0902\#2; -0.58

$792 \pm 0.20 \mu \mathrm{m} / \mathrm{min}$, mean $\pm \mathrm{SEM} ; \mathrm{N}=17)$, Kinesin-13b ${ }^{\text {KVD/KEC }}$-Cerulean/Kinesin-13abc triple KO

793 (GPH0900\#4; -0.94 $\pm 0.08 \mu \mathrm{m} / \mathrm{min}$, mean $\pm \mathrm{SEM} ; \mathrm{N}=10)$, and Kinesin-13b Loop2 $_{\text {-Cerulean/Kinesin- }}$

$79413 a b c$ triple $\mathrm{KO}(\mathrm{GPH} 0901 \# 1 ;-1.05 \pm 0.20 \mu \mathrm{m} / \mathrm{min}$, mean $\pm \mathrm{SEM} ; \mathrm{N}=27)$. Apically directed

795 movement, positive values; basally directed movement, negative values. Points represent individual

796 mitotic events. Results are from one of two independent experiments where at least two independent

797 lines were analysed.

798 (E) Cartoon depicting how subapical and apical cell lengths were measured for (F).

799 (F) Subapical cell length was reduced in the Kinesin-13 KO line (GPH0438\#30; 70.9 $\pm 3.6 \mu \mathrm{m}$ (mean \pm

800 SEM; $\mathrm{N}=26$; $\mathrm{p}$-value $<0.05)$ ) compared to the control (GFP-tubulin/histoneH2B-mRFP; $105.2 \pm 12.4$

$801 \mu \mathrm{m}($ mean $\pm \mathrm{SEM} ; \mathrm{N}=11)$ ). Each point represents individual mitotic events. Results shown are from

802 one of two independent experiments where two independent lines were analysed.

803

804 Figure 4: Kinesin-13 KO moss shows defects in nuclear-proximal MT array, mitotic duration, and 805 spindle length, but shows no difference in spindle flux rate.

806 (A) Mitosis of control (GFP-tubulin/histoneH2B-mRFP), Kinesin-13 KO (GPH0438\#6), and Kinesin-8

$807 \mathrm{KO}$ (GPH0433\#9) moss. Kinesin-13 KO showed reduced metaphase spindle length, retrograde nuclear

808 movement during prophase, increased mitotic duration, and loss of apical bias of nuclear-MTs. Kinesin- 8

809 KO did not show mitotic defects. Bar, $10 \mu \mathrm{m}$; NEBD, 0 min; left, basal side; right, apical side.

810 (B, C) Apical:basal GFP-intensity ratio of GFP-tubulin around the nucleus $1 \mathrm{~min}$ before NEBD was

811 measured as the ratio of GFP-tubulin intensities between apical and basal hemispheric circumference.

812 Control (GFP-tubulin/histoneH2B-mRFP), $1.17 \pm 0.04$ (mean $\pm \mathrm{SEM}$; N=9; p-value $<0.05)$; Kinesin-13

$813 \mathrm{KO}(\mathrm{GPH} 0438 \# 6,30), 1.00 \pm 0.07$ (mean $\pm \mathrm{SEM} ; \mathrm{N}=10$ ). Points represent individual mitotic events.

814 (D) Mitotic duration of control (GFP-tubulin/histoneH2B-mRFP), Kinesin-13 KO (GPH0438\#6, 30),

815 and Kinesin-8 KO (GPH0433\#7, 9) moss as measured from NEBD to anaphase onset. Control, $9.8 \pm 0.3$ 
$816 \min ($ mean $\pm \mathrm{SEM} ; \mathrm{N}=11)$; Kinesin- $13 \mathrm{KO}, 11.8 \pm 0.4 \min ($ mean $\pm \mathrm{SEM}, \mathrm{N}=15 ; \mathrm{p}$-value $<0.001)$.

817 Kinesin- $8 \mathrm{KO}, 9.1 \pm 0.2 \mathrm{~min}$ (mean $\pm \mathrm{SEM} ; \mathrm{N}=10$; $\mathrm{p}$-value $<0.05)$. The duration of prometaphase

818 (from NEBD to chromosome alignment) and metaphase (chromosome alignment to anaphase onset)

819 was also measured and shown. Data shown was pooled from two independent experiments.

820 (E) Spindle length was measured at metaphase (defined as 1 min before anaphase onset) by obtaining the

821 distance between midpoints of apical and basal spindle widths. Control (GFP-tubulin/histoneH2B-

$822 m R F P), 13.0 \pm 0.3 \mu \mathrm{m}($ mean $\pm \mathrm{SEM} ; \mathrm{N}=4)$; Kinesin-13 KO (GPH0438\#30), $11.2 \pm 0.3 \mu \mathrm{m}$ (mean \pm

$823 \mathrm{SEM} ; \mathrm{N}=10$; $\mathrm{p}$-value $<0.01$ ); Kinesin- $8 \mathrm{KO}$ (GPH0433\#9), $12.3 \pm 0.5 \mu \mathrm{m}$ (mean $\pm \mathrm{SEM}$; $\mathrm{N}=10$ ).

824 Points represent individual mitotic events.

825 (F) Spindle poleward flux of control (GFP-tubulin/histoneH2B-mRFP) and Kinesin-13 KO

826 (GPH0438\#30) moss was examined in photobleaching experiments where GFP-tubulin signals on a strip

827 along the metaphase plate was bleached. The bleached regions separating towards the poles are

828 indicative of spindle poleward flux function. Horizontal bar, $5 \mu \mathrm{m}$; vertical bar; $12 \mathrm{~s}$; yellow dashed

829 rectangle in the top panel indicates region used to make time series (bottom panel); cyan dashed rectangle

830 represents bleached region; red lines indicate the segmented lines drawn on the kymograph to obtain flux

831 rate in $(\mathrm{G})$.

832 (G) Quantification of spindle poleward flux experiment as shown in (F). Control, $2.1 \pm 0.2 \mu \mathrm{m} / \mathrm{min}$

833 (mean $\pm \mathrm{SEM} ; \mathrm{N}=22$ ); Kinesin-13 KO, $2.2 \pm 0.4 \mu \mathrm{m} / \min ($ mean $\pm \mathrm{SEM} ; \mathrm{N}=19)$. Points represent

834 individual mitotic events, shown are results from four independent experiments.

836 Figure 5: Kinesin-13 and $-8 \mathrm{KO}$ moss have wavy protonema filaments correlated with unstable MT foci

837 positioning.

838 (A) Protonema filaments of control (GFP-tubulin/histoneH2B-mRFP), Kinesin-13 KO (GPH0438\#30),

839 Kinesin-8 KO (GPH0433\#9) moss. Bar, $50 \mu \mathrm{m}$.

840 (B) Waviness of protonema filaments measured as frequency of wavy bend $\left(>18^{\circ}\right)$ of protonema

841 filaments over measured lengths. Control (GFP-tubulin/histoneH2B-mRFP), $0.006 \pm 0.001 \mu^{-1}$ (mean

$842 \pm \mathrm{SEM} ; \mathrm{N}=28$ filaments); Kinesin-13 KO (GPH0438\#30), $0.024 \pm 0.002 \mu \mathrm{m}^{-1}($ mean $\pm \mathrm{SEM} ; \mathrm{N}=26$

843 filaments; p-value $<0.0001)$; Kinesin- $8 \mathrm{KO}$ (GPH0433\#7), $0.022 \pm 0.005 \mu^{-1}(\operatorname{mean} \pm \mathrm{SEM} ; \mathrm{N}=8$

844 filaments; p-value < 0.01); Cerulean/Kinesin-13 KO (GPH0903\#1), $0.022 \pm 0.004 \mu \mathrm{m}^{-1}$ (mean $\pm \mathrm{SEM}$;

$845 \mathrm{~N}=12$ ); Kinesin-13b(full-length)-Cerulean/Kinesin-13 KO (GPH0899\#10), $0.004 \pm 0.001 \mu \mathrm{m}^{-1}$ (mean

$846 \pm$ SEM; $\mathrm{N}=8 ; \mathrm{p}$-value $<0.0001)$. Points represent individual protonema filaments, results shown are

847 from one experiment of at least four independent experiments.

848 (C) MT foci at tip of caulonema cell of control (GFP-tubulin/histoneH2B-mRFP), Kinesin-13 KO

849 (GPH0438\#30), Kinesin-8 KO (GPH0433\#9) moss. Images were acquired with z-sections at $0.3 \mu \mathrm{m}$ 
850 intervals for $20 \mu \mathrm{m}$ range, and maximum z-projections are displayed. Bottom panels show overlaid time series. Bar, $10 \mu \mathrm{m}$; colours in time series indicate different time points as labelled in top panels.

852 (D) MT foci positions were tracked using FIJI MOSAIC plug-in 2D/3D particle tracker (Sbalzarini and 853 Koumoutsakos, 2005) in time-lapse imaging data as in (C). (x, y) trajectories of three representative MT 854 foci (shown in different colours) for each line are displayed. Each point represents subsequent positions 855 at each time point, at 3 min intervals for $3 \mathrm{~h}$. Same lines as in (B) are represented.

Figure 6: Kinesin-13 localises to the interphase MT network and depletion of Kinesin-13 results in increased shrink rate, reduced catastrophe frequency, increased rescue frequency, and reduced growth rate.

860 (A) MT foci of Kinesin-13c-Citrine/mCherry-tubulin (GPH0100\#15) moss. Image was acquired at 0.3 $861 \mu \mathrm{m}$ intervals for $10 \mu \mathrm{m}$ range; shown is maximum z-projection. Bar, $5 \mu \mathrm{m}$.

862 (B) Interphase MT network of Kinesin-13c-Citrine/mCherry-tubulin (GPH0100\#15) moss. Images were 863 acquired by oblique illumination fluorescence split-view microscopy to avoid chloroplast 864 autofluorescence. Bar, $2 \mu \mathrm{m}$.

865 (C) Kymograph of MT growth taken from imaging as in (B), taken every $3 \mathrm{~s}$. Vertical bar, $2 \mathrm{~min}$; 866 horizontal bar, $5 \mu \mathrm{m}$.

867 (D) Interphase MT plus-end shrink rate of control (GFP-tubulin/histoneH2B-mRFP, $0.245 \pm 0.012 \mu \mathrm{m} / \mathrm{s}$ 868 (mean $\pm \mathrm{SEM} ; \mathrm{N}=25$ cells $)$ ) and Kinesin $-13 \mathrm{KO}(\mathrm{GPH} 0438 \# 30,0.429 \pm 0.021 \mu \mathrm{m} / \mathrm{s}(\mathrm{mean} \pm \mathrm{SEM}$; $\mathrm{N}$ $869=25$ cells; -value $<0.0001)$ ) moss. Points represent individual cells; results shown are from one 870 experiment of two independent experiments.

871 (E) Interphase MT catastrophe frequency of control (GFP-tubulin/histoneH2B-mRFP, $9.3 \pm 1.2 \times 10^{-3} / \mathrm{s}$ 872 (mean $\pm \mathrm{SEM} ; \mathrm{N}=33$ cells $)$ ) and Kinesin-13 KO $\left(\mathrm{GPH} 0438 \# 30,2.2 \pm 0.5 \times 10^{-3} / \mathrm{s}(\right.$ mean $\pm \mathrm{SEM} ; \mathrm{N}=$ 87328 cells; $p$-value $<0.0001)$ ). Points represent individual cells; results shown are from two independent 874 experiments.

875 (F) Interphase MT rescue frequency of control (GFP-tubulin/histoneH2B-mRFP, $14 \pm 3 \times 10^{-3} / \mathrm{s}$ (mean \pm $876 \mathrm{SEM} ; \mathrm{N}=25$ cells $)$ ) and Kinesin- $13 \mathrm{KO}\left(\mathrm{GPH} 0438 \# 30,25 \pm 6 \times 10^{-3} / \mathrm{s}\right.$ (mean $\pm \mathrm{SEM} ; \mathrm{N}=23$ cells)).

877 Points represent individual cells; results shown are from two independent experiments.

878 (G) Interphase MT plus-end growth rate of control (EB1-Citrine/mCherry-tubulin, GPH0379\#2, $0.147 \pm$ $8790.013 \mu \mathrm{m} / \mathrm{s}$ (mean $\pm \mathrm{SEM} ; \mathrm{N}=5$ cells, $50 \mathrm{MTs})$ ) and Kinesin-13 KO moss (GPH0577\#11, $0.093 \pm$ $8800.003 \mu \mathrm{m} / \mathrm{s}($ mean $\pm \mathrm{SEM} ; \mathrm{N}=5$ cells, $50 \mathrm{MTs}$; $\mathrm{p}$-value $<0.05)$ ). Points represent individual cells.

881 (H) Simulation of MT growth of 4,000 MTs in 4 min based on a probability model established using MT 882 dynamics parameters from in vivo interphase MT dynamics analyses (D-G) (refer to Materials \& 883 Methods, and Table 1). Control MT dynamics parameters yielded approximately normal distributions of 
884 MT lengths and tended to have a larger population of MTs with longer lengths, with the longest $25 \%$ of

885 MTs ranging between 23.4 to $59.8 \mu \mathrm{m}$ in length. For MTs under Kinesin-13 KO conditions, the

886 distribution of MT length was narrower, with $50 \%$ of all MTs between 11.5 to $22.6 \mu \mathrm{m}$ lengths, whereas

887 the longest $25 \%$ of MTs ranged from 22.6 to $29.4 \mu \mathrm{m}$ in length. Histogram bin width $=0.5 \mu \mathrm{m}$.

888

889 Figure 7: Recombinant Kinesin-13 does not depolymerise stabilised GMPCPP-MT seeds but shows MT

890 catastrophe inducing activity.

891 (A) Protein domains of Kinesin-13b and recombinant Kinesin-13b ${ }^{\text {motor }}$-mGFP construct. Protein

892 domains were determined using InterPro. His-tag for affinity purification was attached to C-terminus of

893 the recombinant protein.

894 (B) In vitro MT depolymerisation assay using GMPCPP-stabilised MT seeds was performed using

895 purified DmKLP10A, recombinant Kinesin-13b ${ }^{\text {motor }}$-mGFP construct, AtMIDD1, AtMIDD1 and

896 Kinesin-13b ${ }^{\text {motor }}$-mGFP construct, and also under buffer only conditions. Only DmKLP10A

897 successfully depolymerised MT seeds. The slight reduction in intensity in the bottom panels is due to

898 photobleaching during imaging. All proteins were used at $200 \mathrm{nM}$ except for AtMIDD1 which was at

$899100 \mathrm{nM}$. Bar, $5 \mu \mathrm{m}$.

900 (C) Representative kymographs of in vitro MT dynamics polymerisation assays with Kinesin-13b ${ }^{\text {motor }}$

901 mGFP construct at $0,0.3$, and $1.5 \mu \mathrm{M}$. Time-lapse imaging was performed with TIRF microscopy

902 taken every $3 \mathrm{~s}$. Brightness and contrast was manually adjusted. Vertical bar, $2 \mathrm{~min}$; horizontal bar; 5

$903 \mu \mathrm{m}$.

904 (D-G) In vitro MT dynamics parameters were analysed from time-lapse imaging of $i n$ vitro MT

905 dynamics polymerisation assays with Kinesin- $13 b^{\text {motor }}$-mGFP construct at $0,0.15,0.3,0.6$, and $1.5 \mu \mathrm{M}$

906 taken using TIRF microscopy at every $3 \mathrm{~s}$. In particular, growth rate was observed to reduce slightly,

907 from $9.0 \pm 0.4 \times 10^{-3} \mu \mathrm{m} / \mathrm{s}$ (mean $\pm \mathrm{SEM} ; \mathrm{N}=3$ ) in buffer only conditions, to $7.5 \pm 0.7 \times 10^{-3} \mu \mathrm{m} / \mathrm{s}$ (mean

$908 \pm \mathrm{SEM} ; \mathrm{N}=3)$ in $1.5 \mu \mathrm{M}$ protein. Catastrophe frequency was observed to reproducibly increase with

909 high concentrations of Kinesin- $13 \mathrm{~b}^{\text {motor }}$-mGFP, having a catastrophe frequency of $2.3 \pm 0.2 \times 10^{-3} / \mathrm{s}$

910 (mean $\pm \mathrm{SEM} ; \mathrm{N}=3$ ) at $1.5 \mu \mathrm{M}$ protein, compared to $1.2 \pm 0.3 \times 10^{-3} / \mathrm{s}$ in buffer only conditions. Points

911 represent mean values from independent experiments.

912

913 Figure 8: Recombinant Kinesin-8 motor does not depolymerise MTs but shows MT gliding activity.

914 (A) Protein domains of Kinesin-8II and recombinant Kinesin- $8 \mathrm{II}^{\text {motor }}$-GFP construct. Protein domains

915 were identified using InterPro. His-tag for affinity purification was attached to C-terminus of the

916 recombinant protein.

917 (B) In vitro MT depolymerisation assay using GMPCPP-stabilised MT seeds was performed using

918 purified ScKip3, recombinant Kinesin-8II ${ }^{\text {motor }}$-GFP, and also under buffer only conditions. Only 
919 ScKip3 showed MT depolymerisation activity. The slight reduction in intensity in bottom panels is due

920 to photobleaching during imaging. All proteins were used at $200 \mathrm{nM}$. Bar, $10 \mu \mathrm{m}$.

921 (C) ATP-dependent MT gliding velocity of Kinesin-8II ${ }^{\text {motor }}$-GFP. $1 \mathrm{mM} \mathrm{ATP,} 0.68 \pm 0.03 \mu \mathrm{m} / \mathrm{min}$

922 (mean $\pm \mathrm{SEM} ; \mathrm{N}=124 \mathrm{MTs}$ ); $5 \mathrm{mM}$ ATP, $1.18 \pm 0.02 \mu \mathrm{m} / \mathrm{min}$ (mean $\pm \mathrm{SEM}$; $\mathrm{N}=121 \mathrm{MTs}$, $\mathrm{p}$-value

$923<0.0001)$.

924 (D) In vitro MT gliding assay using GMPCPP-stabilised MTs on Kinesin-8II ${ }^{\text {motor }}$-GFP which was

925 immobilised on glass, at 0,1 , and $5 \mathrm{mM}$ ATP. Red dotted line in top panel indicates segmented line

926 used to draw kymographs (bottom panels). Gliding activity of Kinesin-8II ${ }^{\text {motor }}$-GFP was verified in 3

927 independent experiments. Vertical bar, $45 \mathrm{~s}$; horizontal bar, $2 \mu \mathrm{m}$.

928 

certified by peer review) is the author/funder, who has granted bioRxiv a license to display the preprint in perpetuity. It is made available under aCC-BY-NC 4.0 International license.

A

Đcoiled coil $\square$ motor $\square$ neck
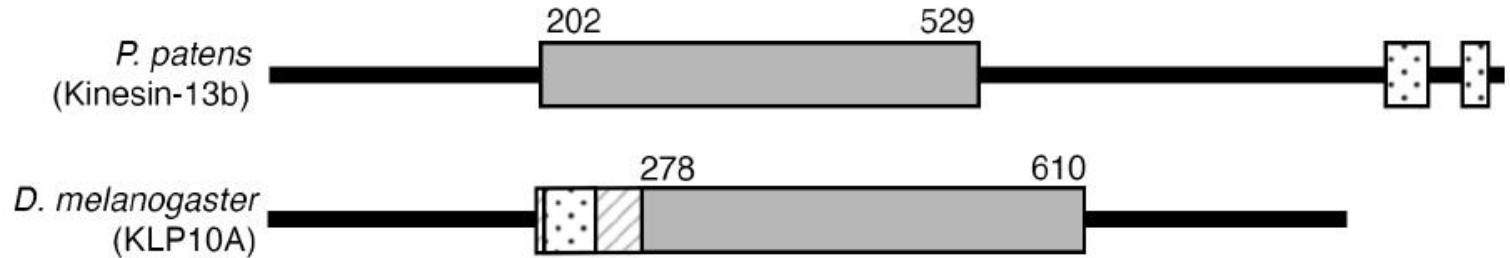

(KLP10A)

P. patens

(Kinesin-8II)

255

595

10

436

S. cerevisiae

(Kip3)

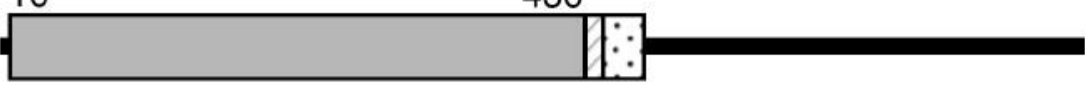

100 a.a.

B

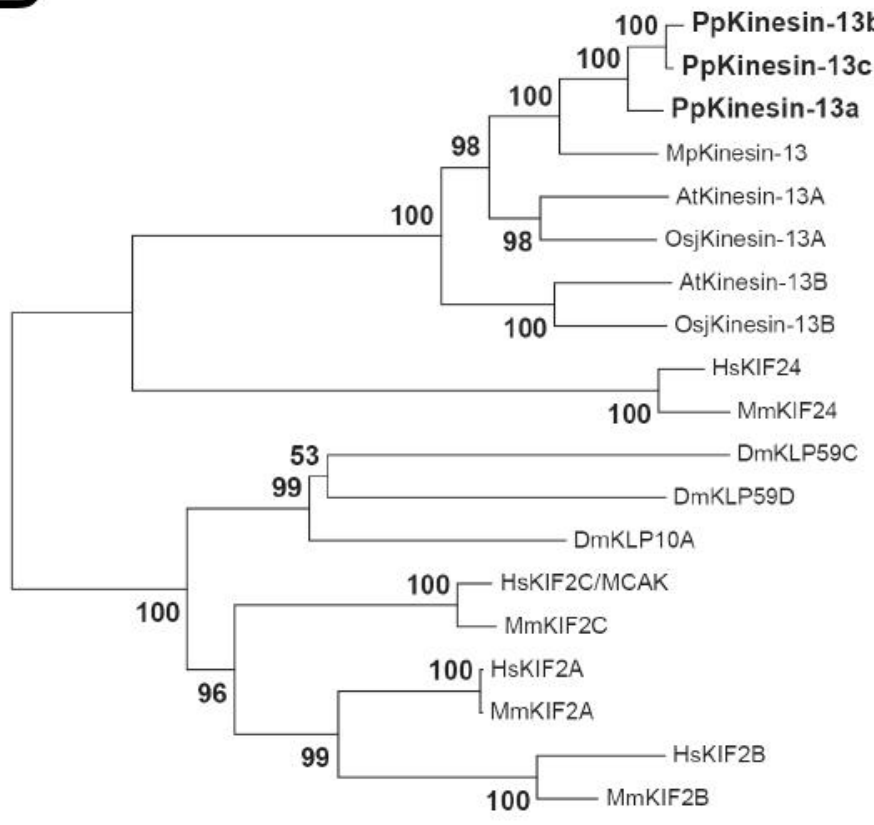

0.1

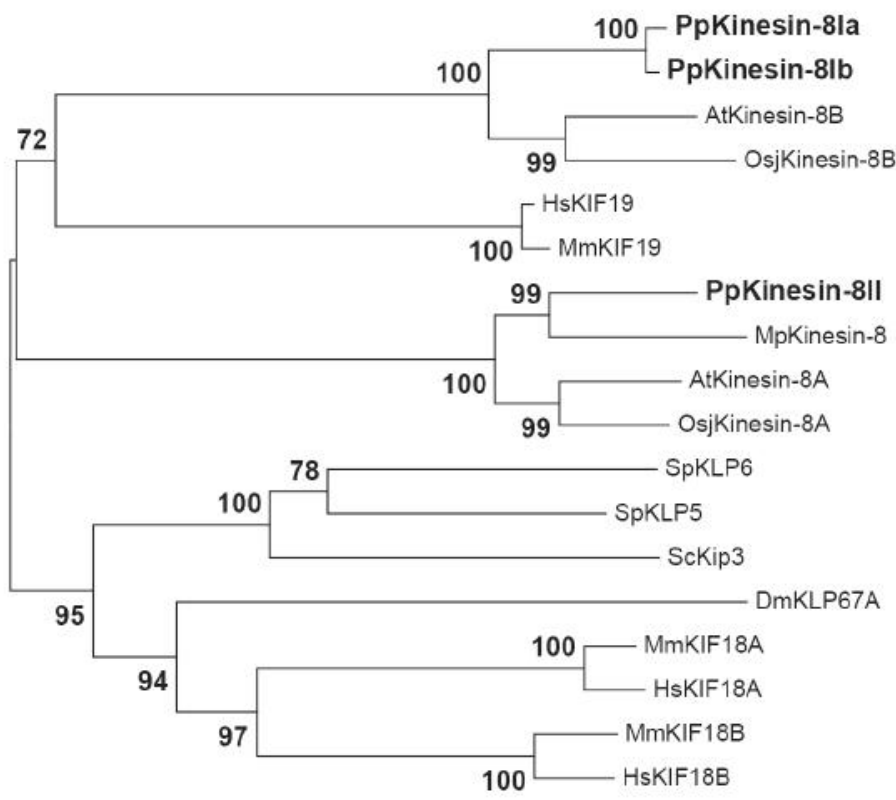

0.1

Figure 1: Conservation of Kinesin-13 and Kinesin-8 in the moss Physcomitrella patens.

(A) Protein domains of Kinesin-13 (represented with Kinesin-13b) and Kinesin-8 (represented with Kinesin-8II) of moss, compared against Drosophila melanogaster KLP10A/Kinesin-13 and budding yeast Saccharomyces cerevisiae Kip3/Kinesin-8. Domains of Drosophila and budding yeast proteins were referenced from UniProt, whereas moss protein domains were predicted using InterPro. (B, C) Kinesin-13 and -8 phylogeny across the moss Physcomitrella patens, the Brassicaceae Arabidopsis thaliana, the liverwort Marcantia polymorpha, the rice Oryza sativa subspecies Japonica, the fruit fly Drosophila melanogaster, mammalians Mus muculus and Homo sapiens, and also for Kinesin-8 in budding yeast Saccharomyces cerevisiae and fission yeast Schizosaccharomyces pombe. After amino acid sequences were aligned with MAFFT, gapped regions were removed manually using MacClade. The phylogenetic tree was constructed using neighbour-joining methods using the Molecular Evolutionary Genetics Analysis (MEGA) software. Reliability was assessed with 1,000 bootstrapping trials. Horizontal branch length is proportional to the estimated evolutionary distance. Protein sequences are presented in supplemental dataset. Bar, 0.1 amino acid substitution per site. 


\section{Figure 2}

bioRxiv prefofint doi: https://doi.org/10.1101/819722; this version posted October 2019. The copyright holder for this preprint (which was not

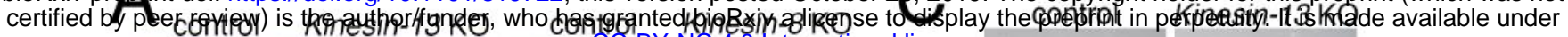
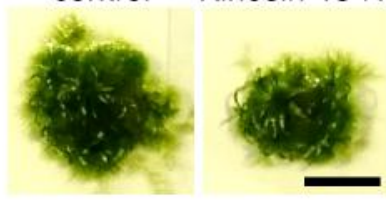

B

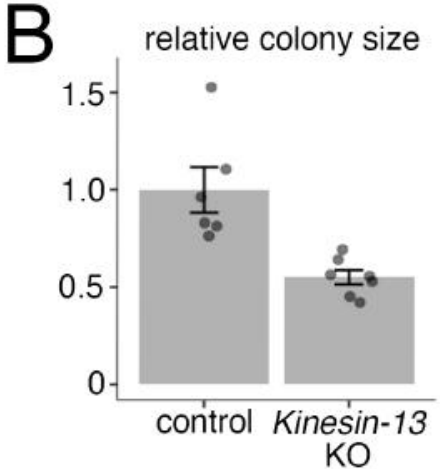

D
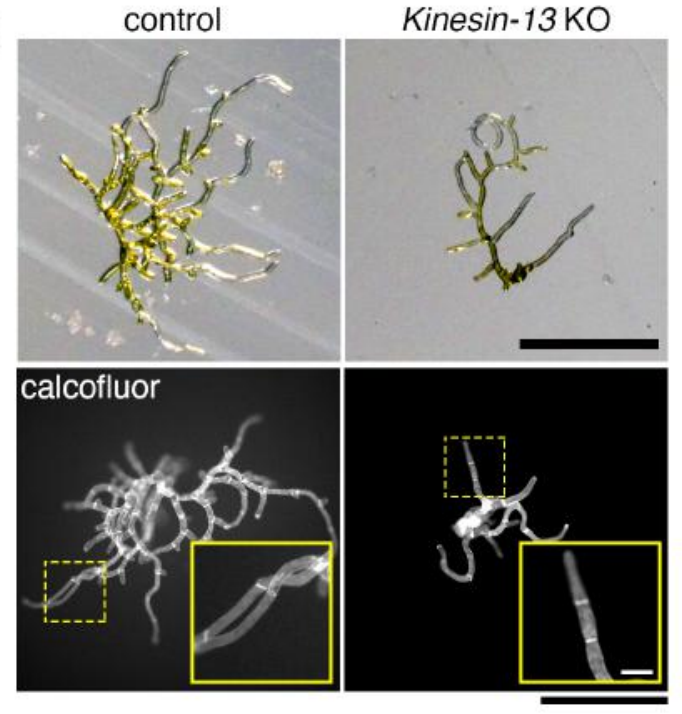

E
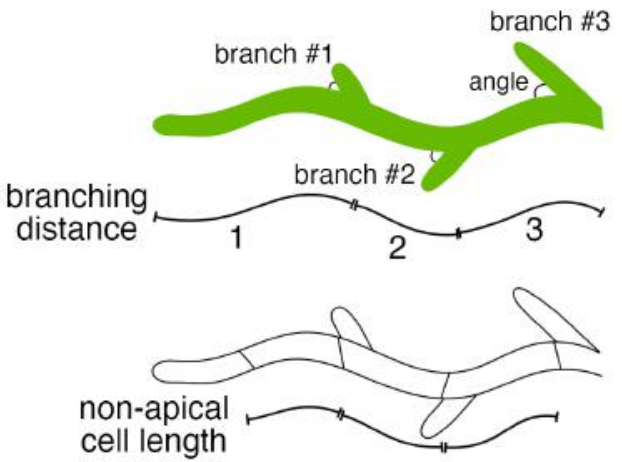

Kinesin-13 KO
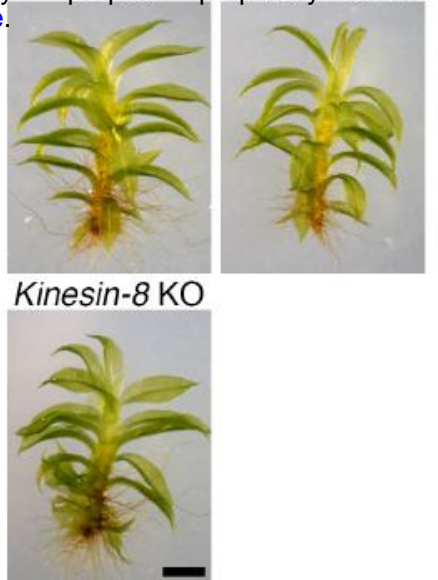

F
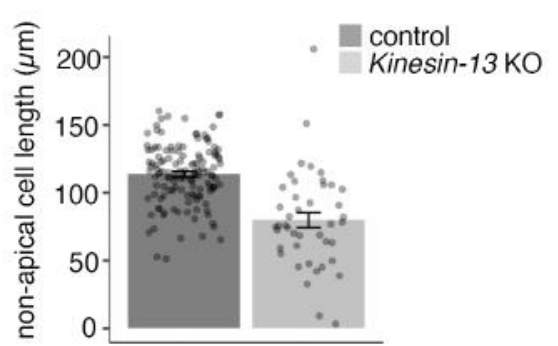

G
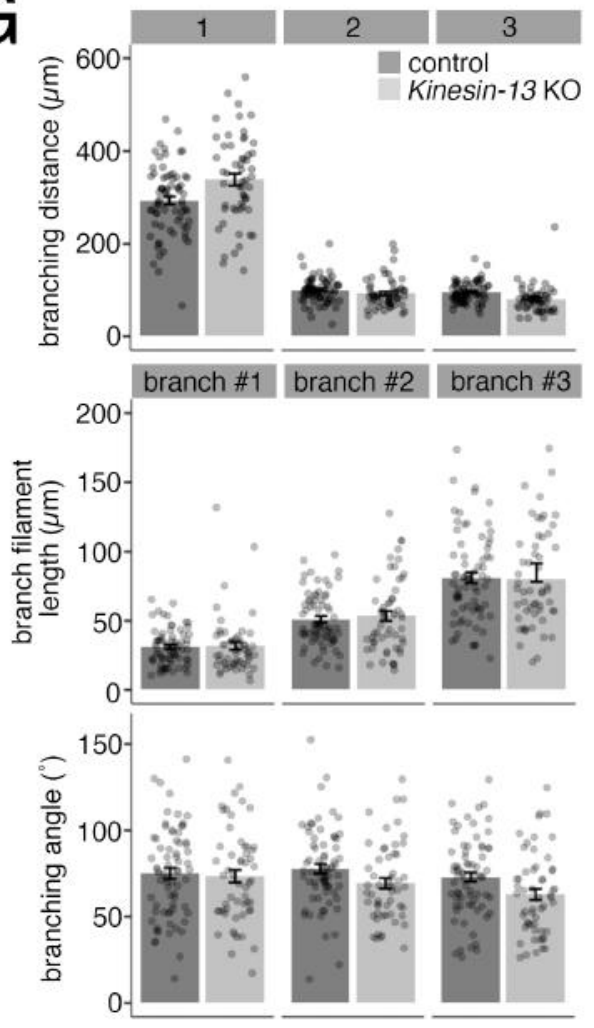

Figure 2: Kinesin-13 and $-8 \mathrm{KO}$ mosses are morphologically normal, but Kinesin-13 KO moss shows retarded growth and reduced cell length.

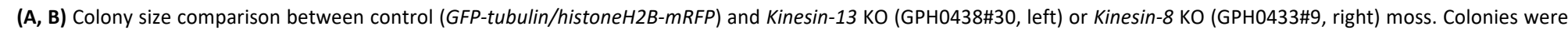

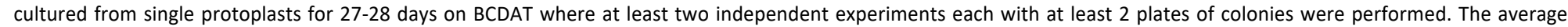

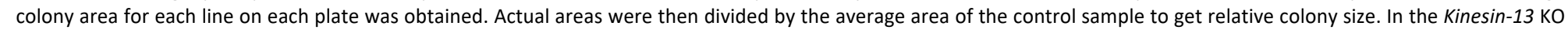

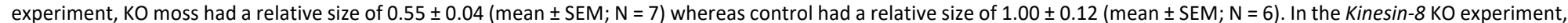

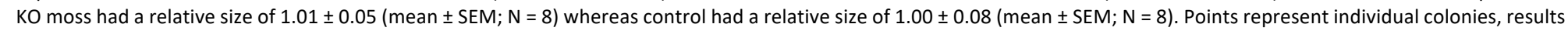

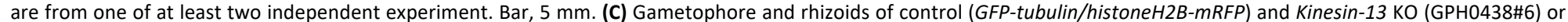

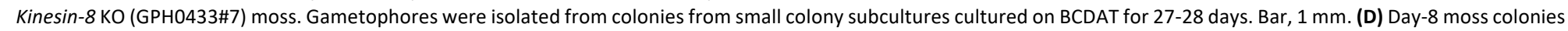

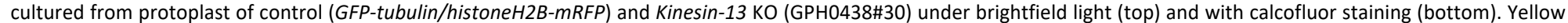

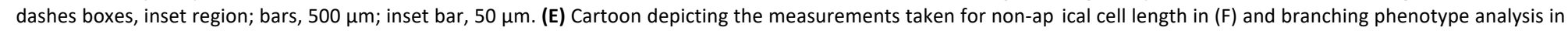

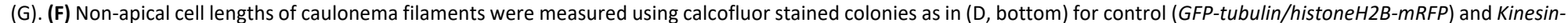

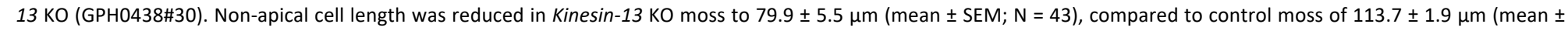

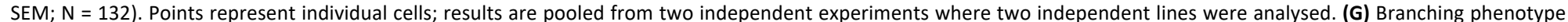

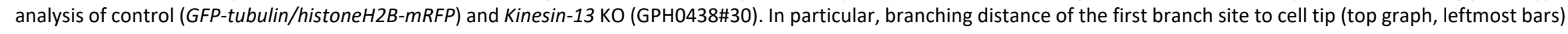

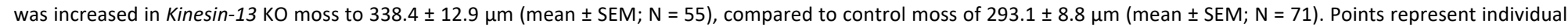
filaments; results are pooled from two independent experiments where two independent lines were analysed. 


\section{Figure 3}

bioRxiv prepint doi: https://doi.org/10.1101/819722; this version posted 0 ober 28, 2019. The copyright holder for this preprint (which was not

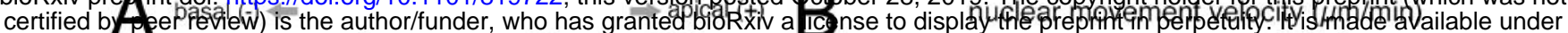
control
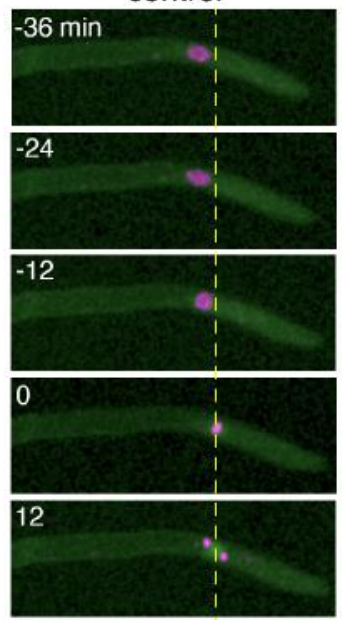

24
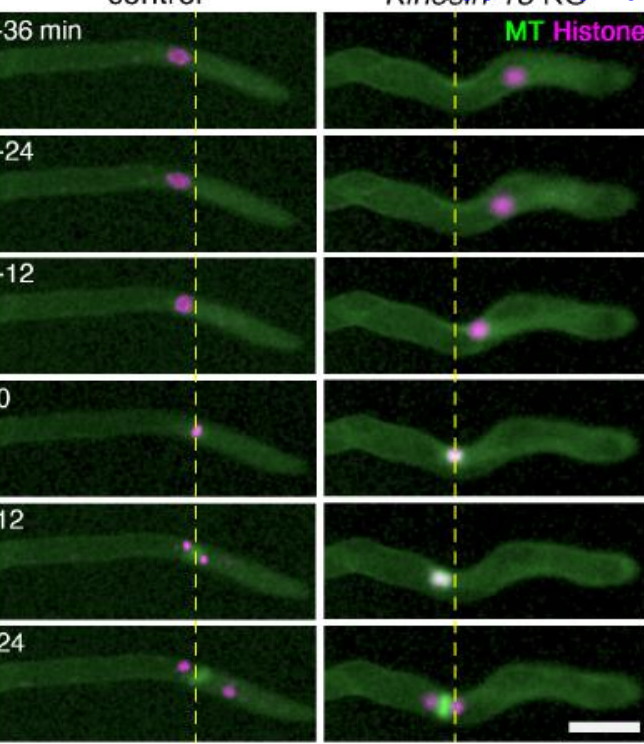

C

$\square$ motor $\square$ coiled coil $\square$ Cerulean

Kinesin-13b(full-length)-Cerulean (FL)

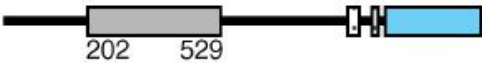

Kinesin-13b $b^{\text {RIG }}$-Cerulean (RIG)

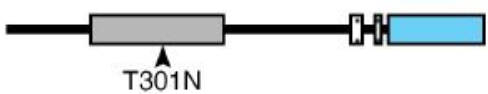

Kinesin-13b KVD/KEC $_{\text {-Cerulean (KVD/KEC) }}$

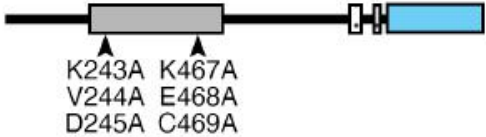

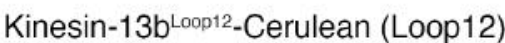
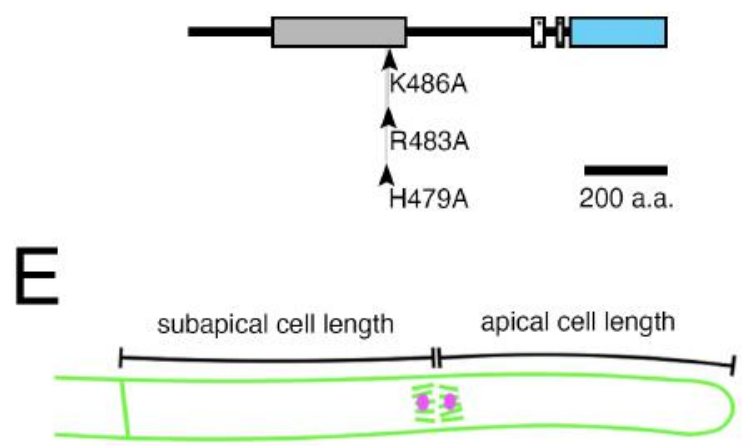

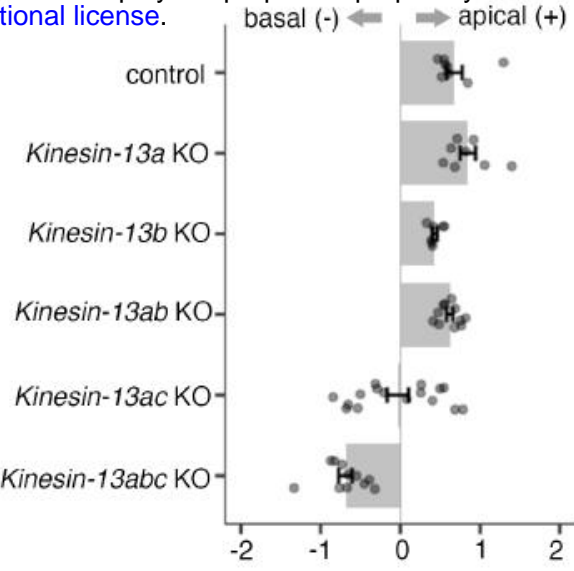

D

nuclear movement velocity $(\mu \mathrm{m} / \mathrm{min})$

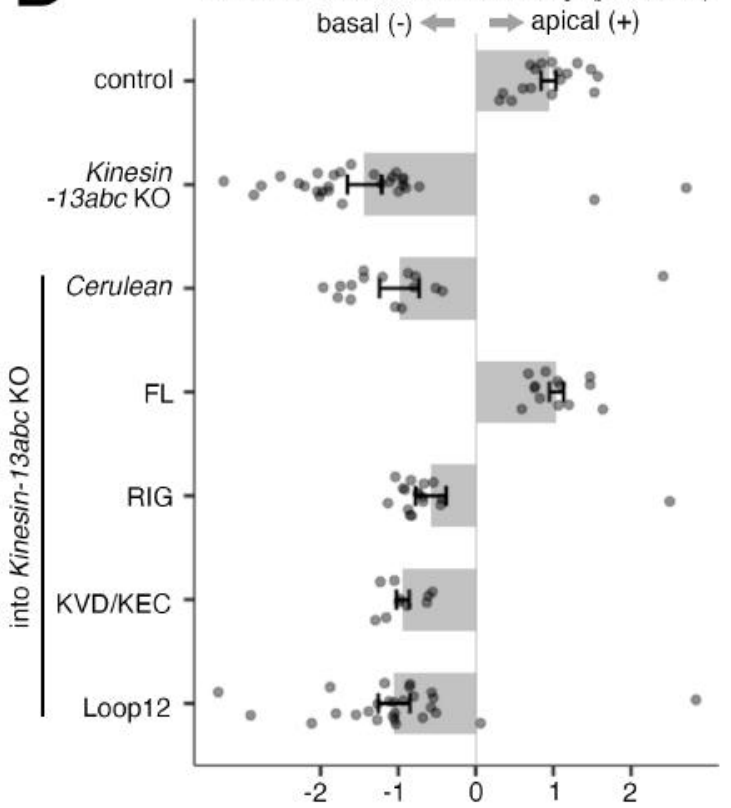

E

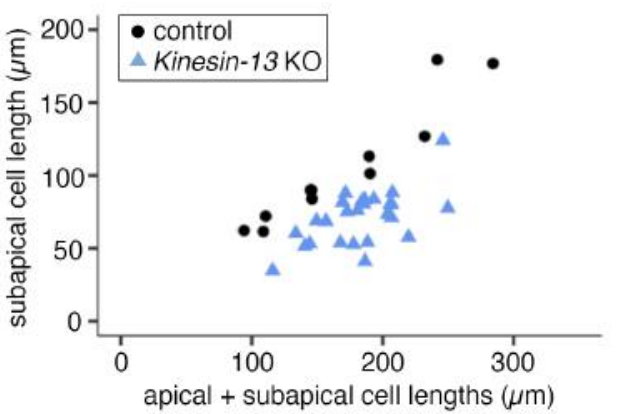

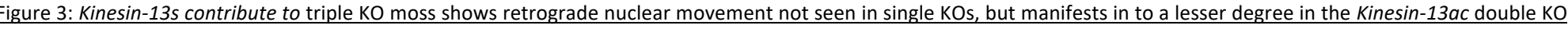
line.

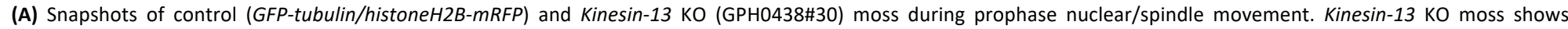

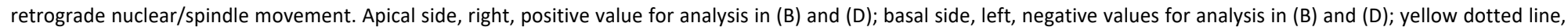

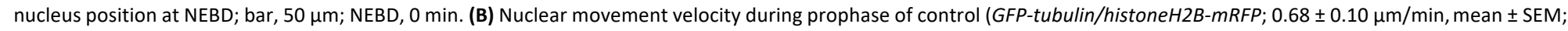

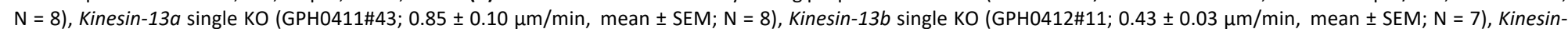

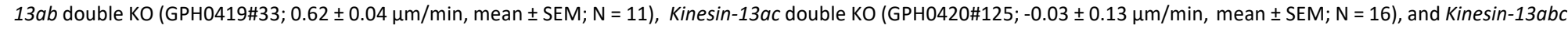

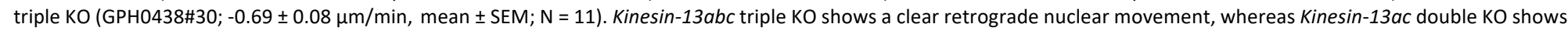

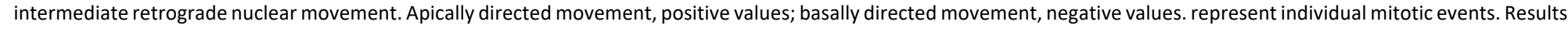

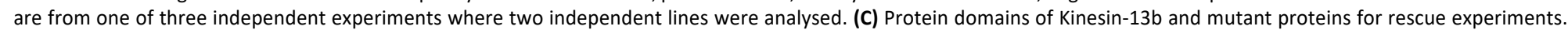

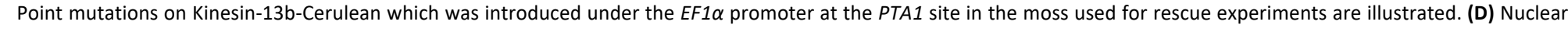

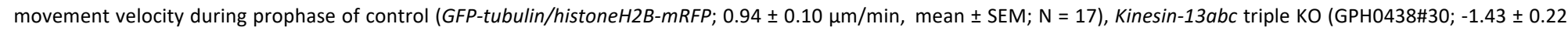

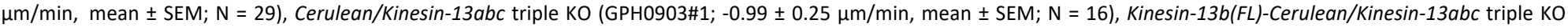

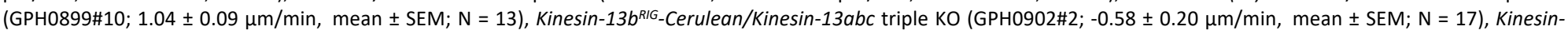

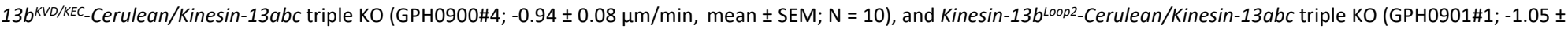

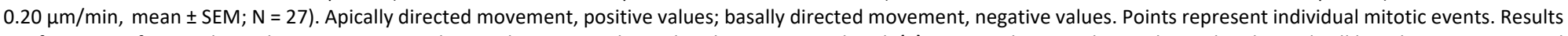

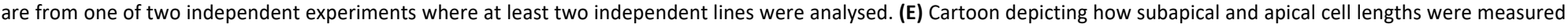

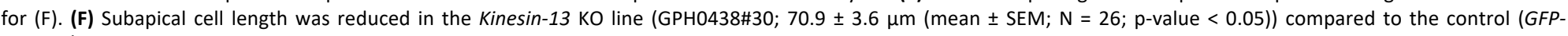

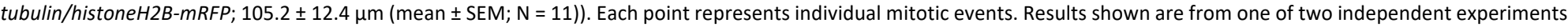
where two independent lines were analysed. 


\section{Figure 4}

bioRxiv preprint doi: https://doi.org/10.1101/819722; this version posted October 28, 2019. The copyright holder for this preprint (which was not certifi $\mathrm{A}$ by peer review) is the author/funder, who has granted bioRxiv a license to display peprint in perpetuity. It is made available under

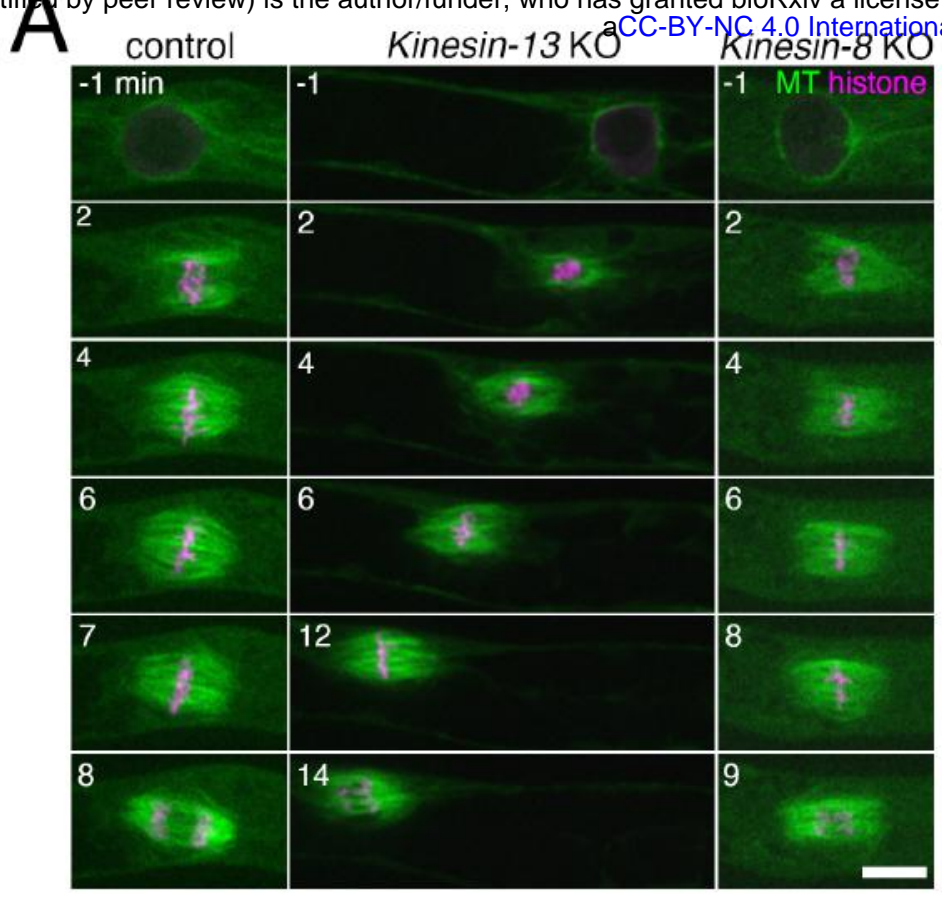

\section{B}

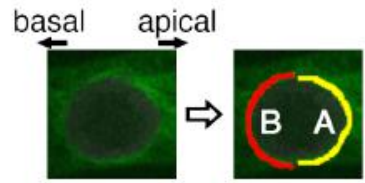

mean pixel intensity of $\mathrm{A}$ mean pixel intensity of $\mathbf{B}$ apical:basal

= GFP-intensity ratio

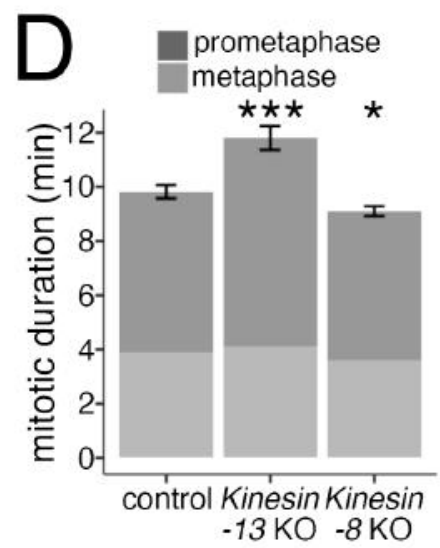

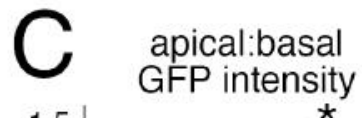

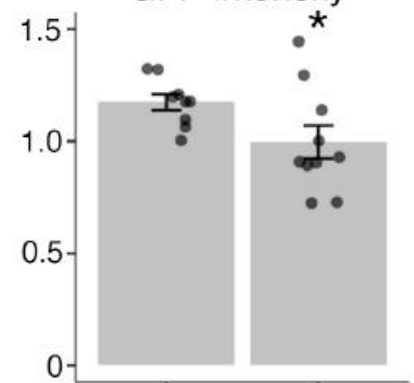

control Kinesin-13 KO
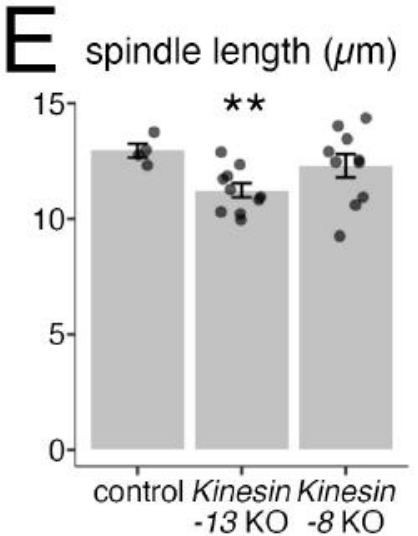

control
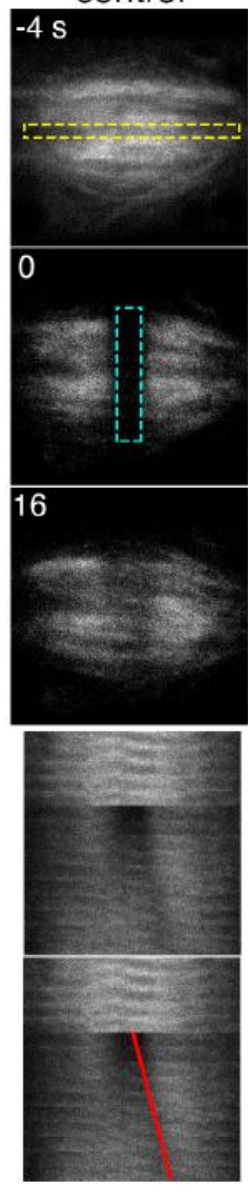

G
Kinesin-13 KO
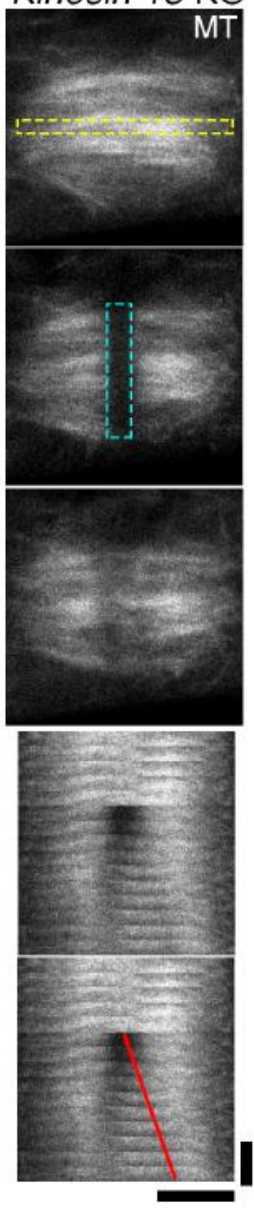

flux rate $(\mu \mathrm{m} / \mathrm{min})$

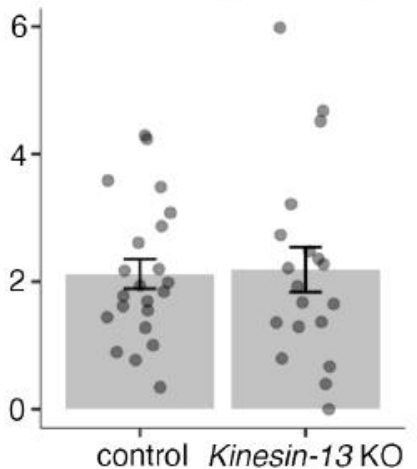

Figure 4: Kinesin-13 KO moss shows defects in nuclear-proximal MT array, mitotic duration, and spindle length, but shows no difference in spindle flux rate.

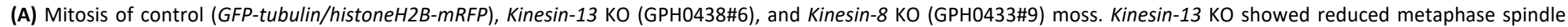

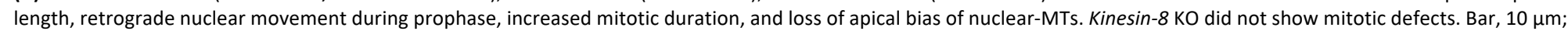

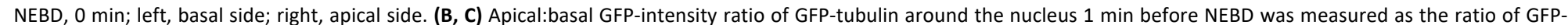

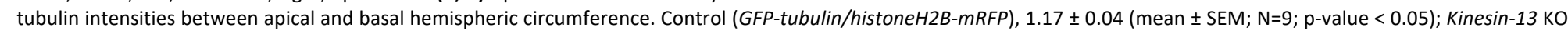

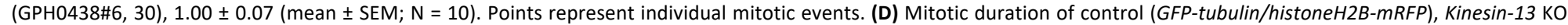

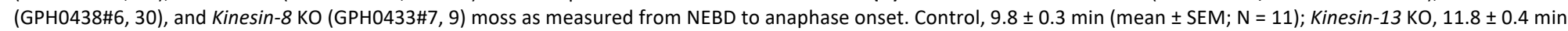

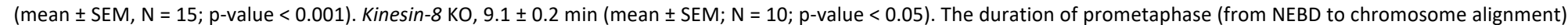

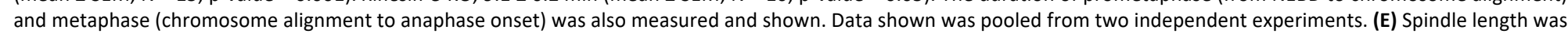

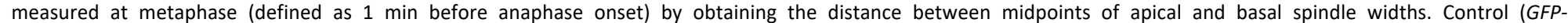

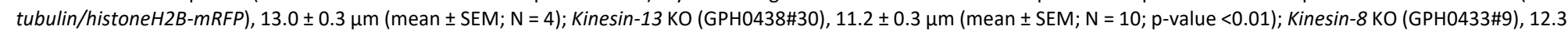

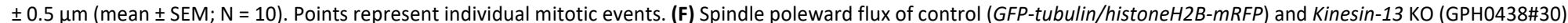

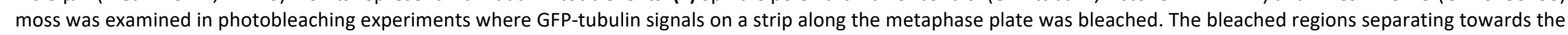

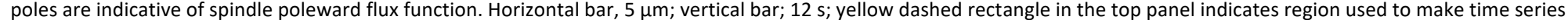

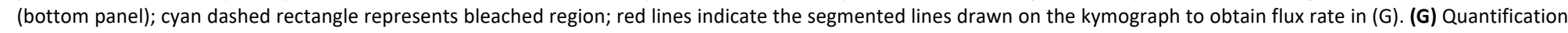

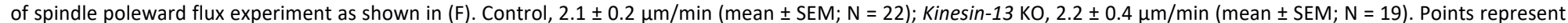
individual mitotic events, shown are results from four independent experiments. 


\section{Figure 5}

bioRxiv preprint doi: https://doi.org/10.1101/819722; this version posted October 28, 2019. The copyright holder for this preprint (which was not certifie (by peer review) is the author/funder, who has granted bioRxiy icense to display the preprint in perpetuity. It is made available under

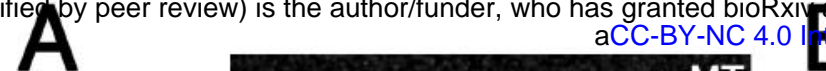
-
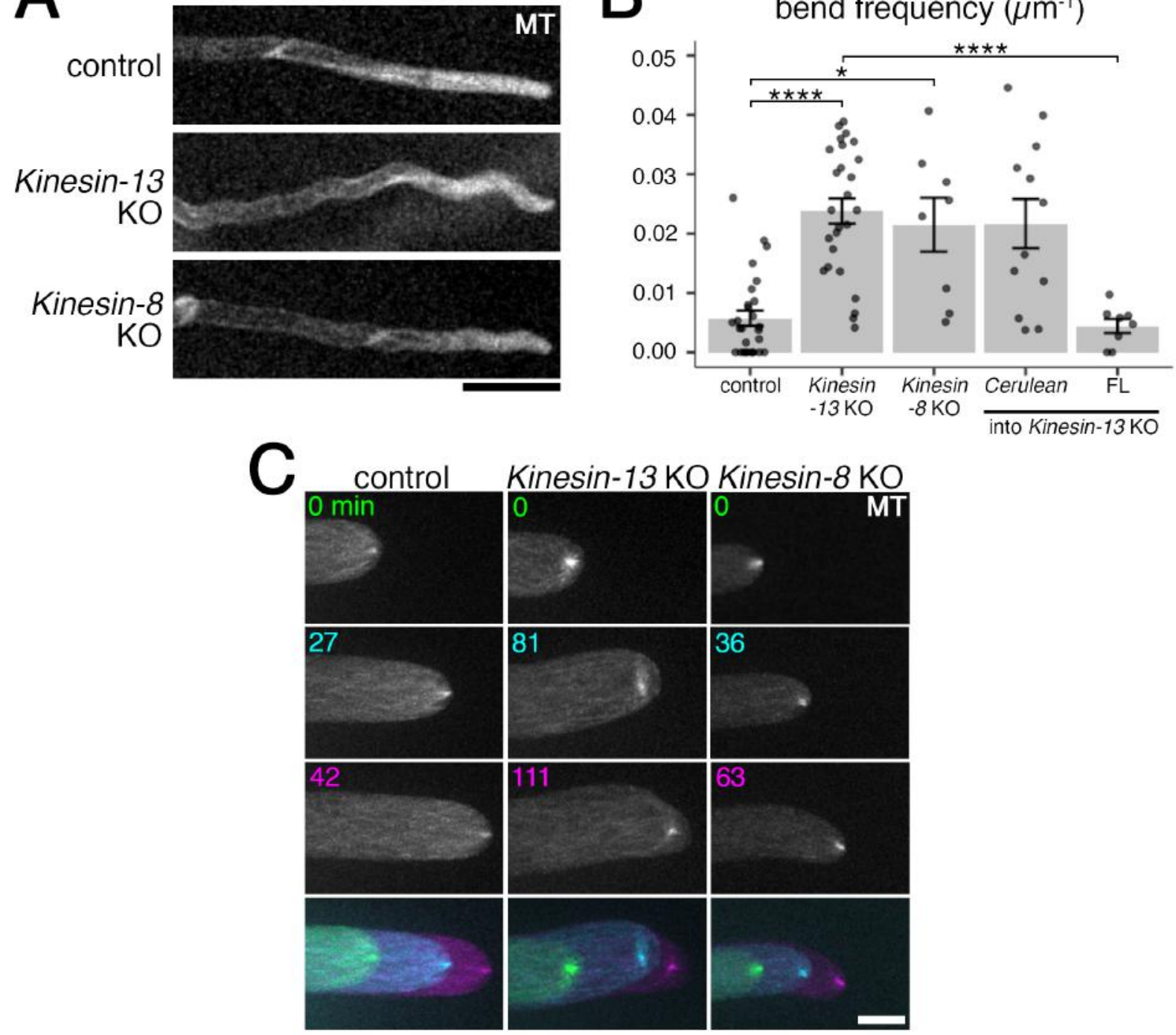

D
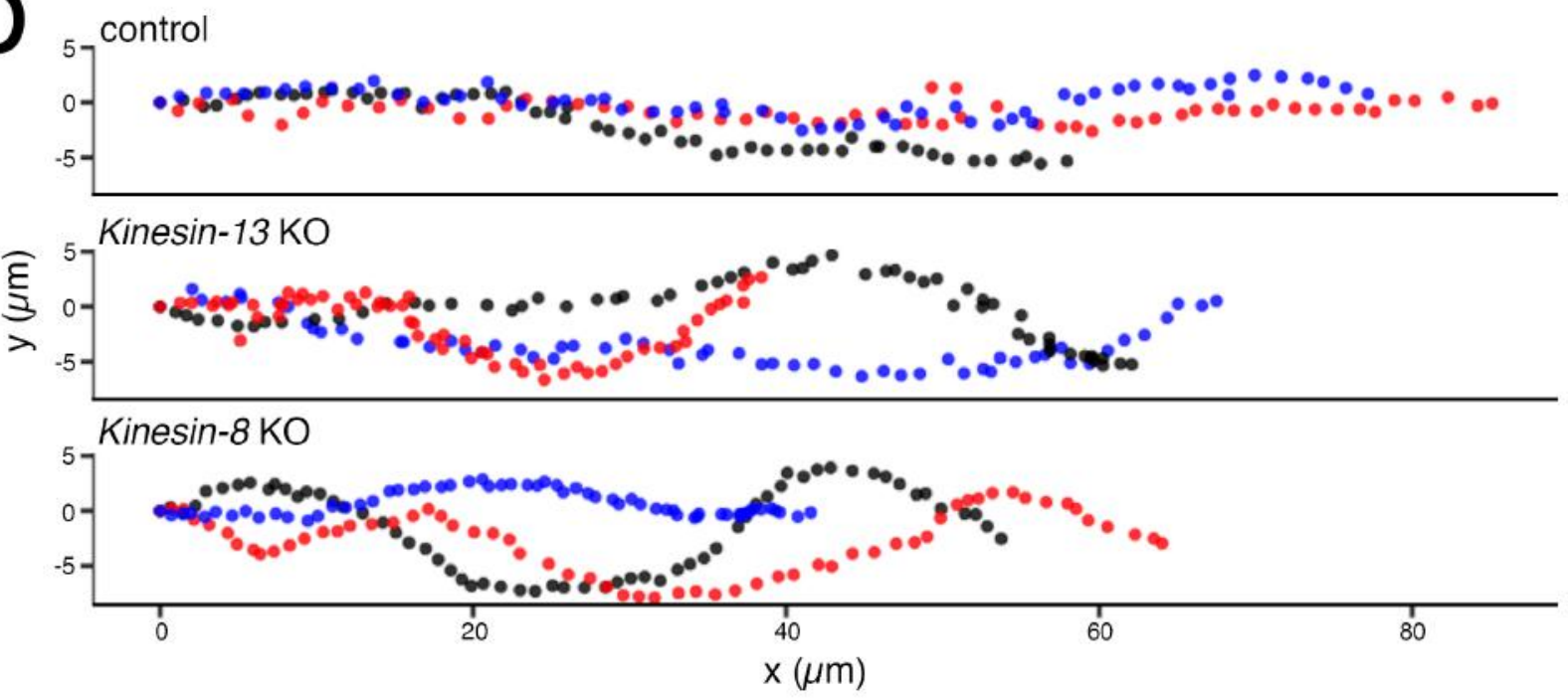

Figure 5: Kinesin-13 and -8 KO moss have wavy protonema filaments correlated with unstable MT foci positioning.

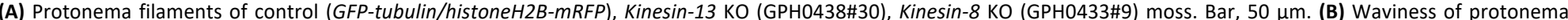

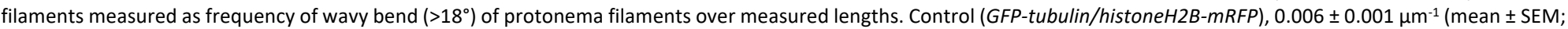

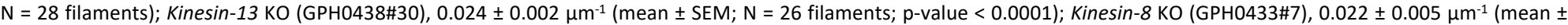

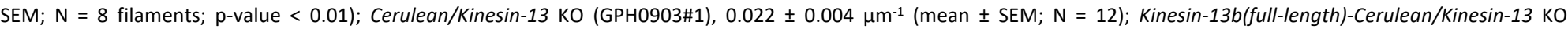

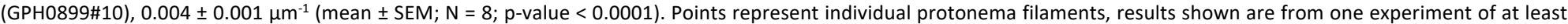

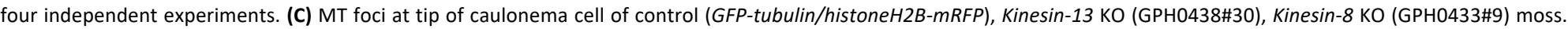

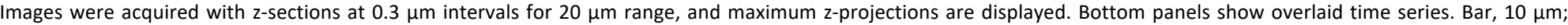

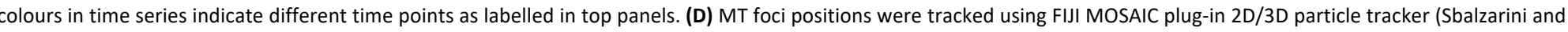

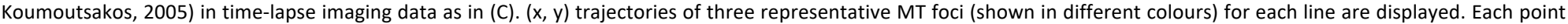
represents subsequent positions at each time point, at $3 \mathrm{~min}$ intervals for $3 \mathrm{~h}$. Same lines as in (B) are represented. 


\section{Figure 6}

bioRxi/Apreprint doi: https://doi.org/10.1101/819722; th STersion posted October 28, 2019. The copyrig/t holder for this preprint (which was not certiff-alby peer review) is the author/funder, who has granted bioRxiv a license to display the preprint in perpetuity. It is made available under
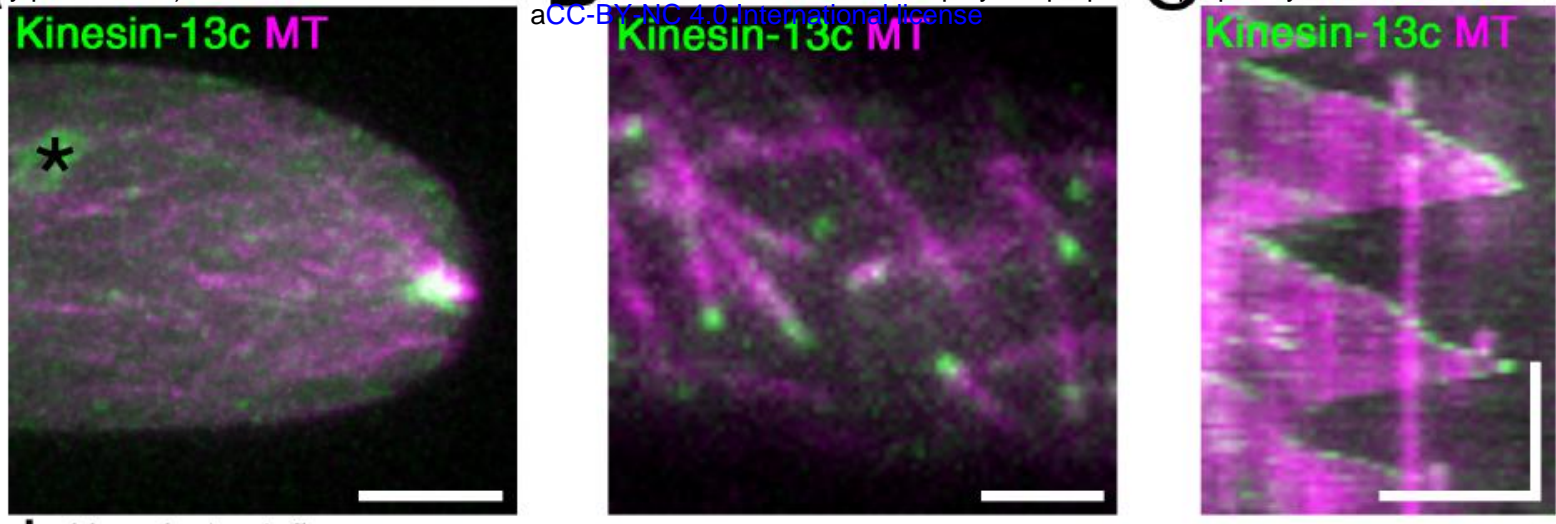

丈 chloroplast autofluorescence
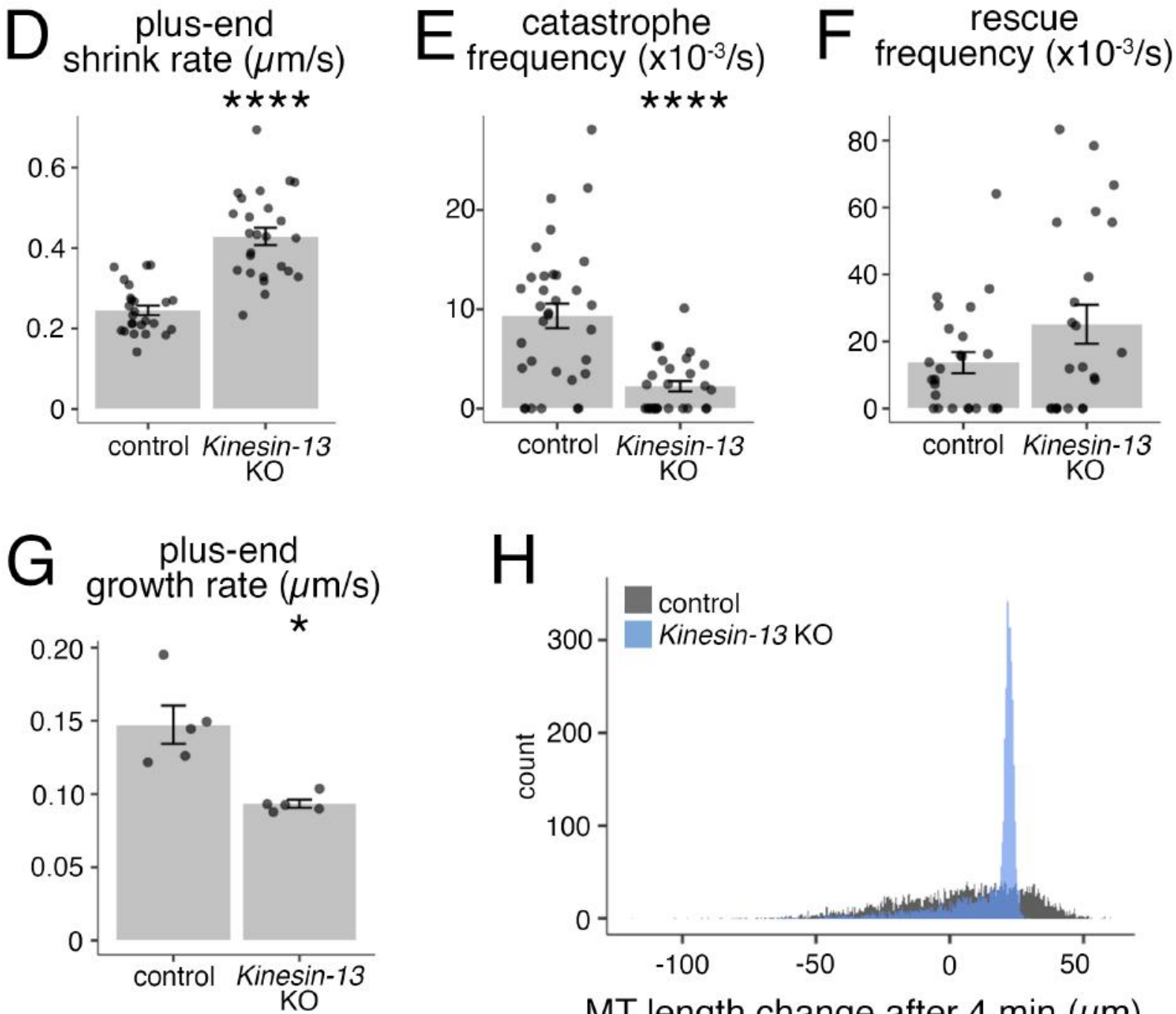

\section{MT length change after $4 \mathrm{~min}(\mu \mathrm{m})$}

Figure 6: Kinesin-13 localises to the interphase MT network and depletion of Kinesin-13 results in increased shrink rate, reduced catastrophe frequency, increased rescue frequency, and reduced growth rate.

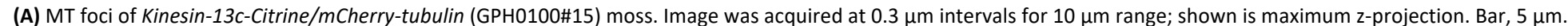

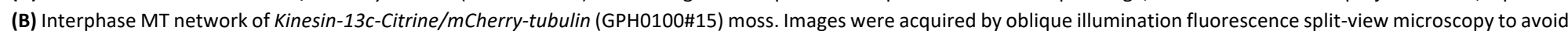

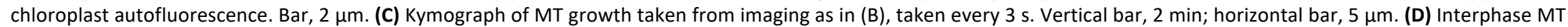

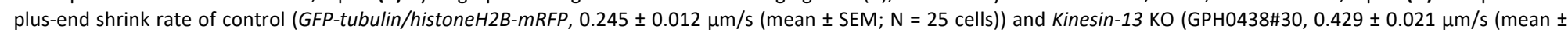

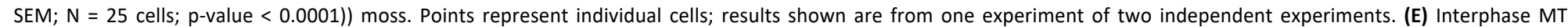

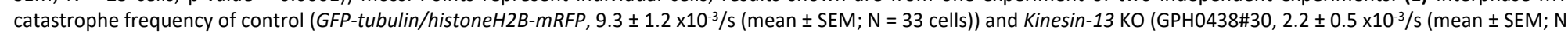

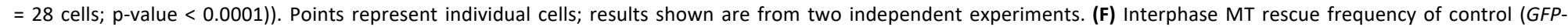

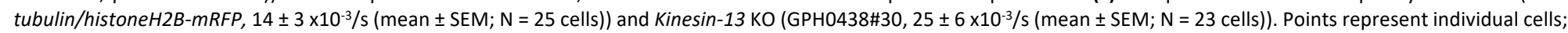

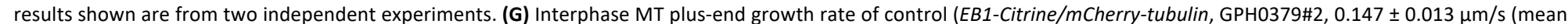

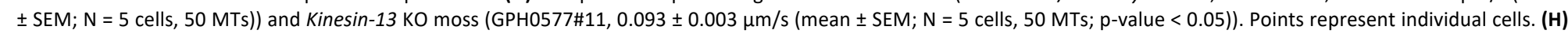

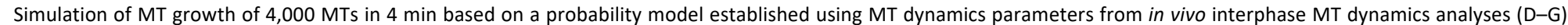

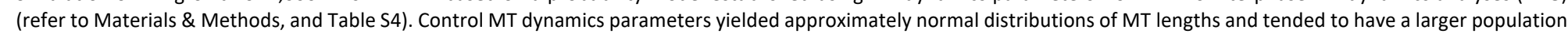

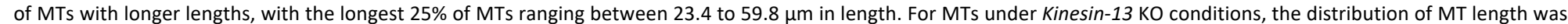
narrower, with $50 \%$ of all MTs between 11.5 to $22.6 \mu \mathrm{m}$ lengths, whereas the longest $25 \%$ of MTs ranged from 22.6 to $29.4 \mu \mathrm{m}$ in length. Histogram bin width $=0.5 \mu \mathrm{m}$. 


\section{Figure 7}

bioRxiv preprint doi: https://doi.org/10.1101/819722; this version posted October 28, 2019. The copyright holder for this preprint (which was not

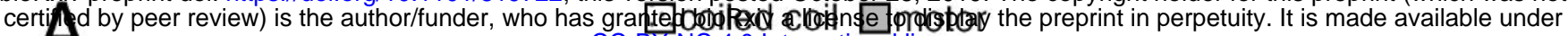
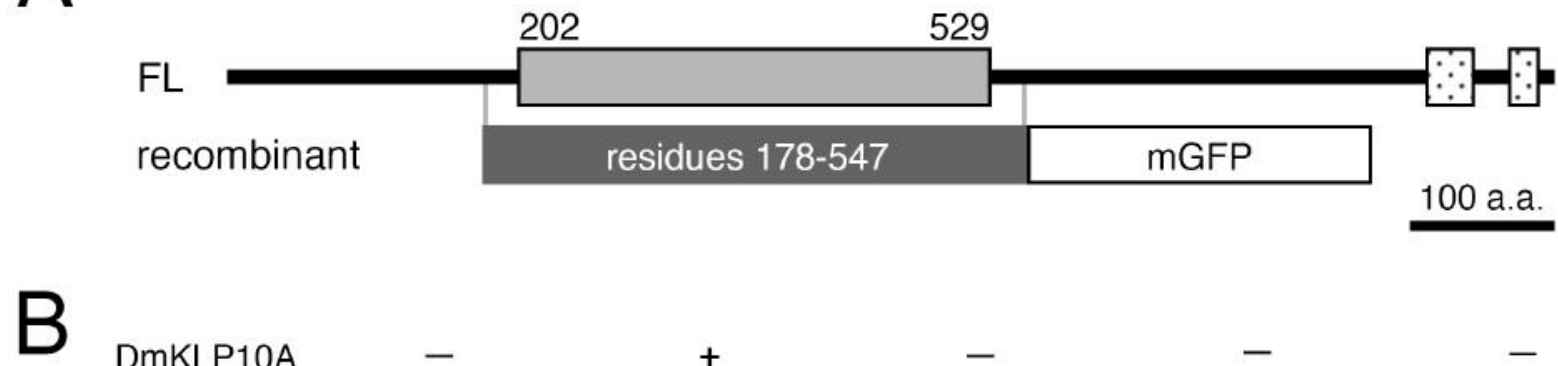

DMKLP10A AtMIDD1

PpKinesin-13b
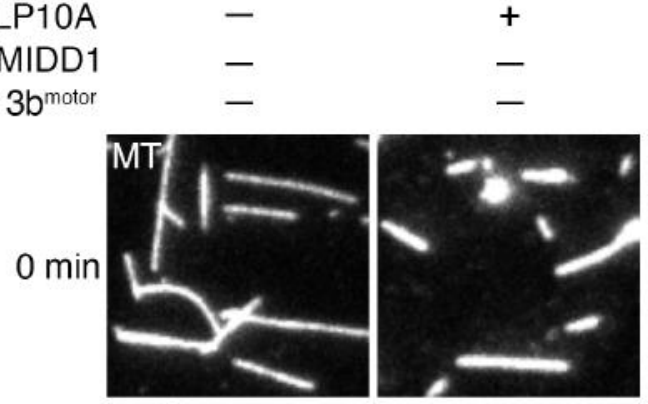

$10 \min$
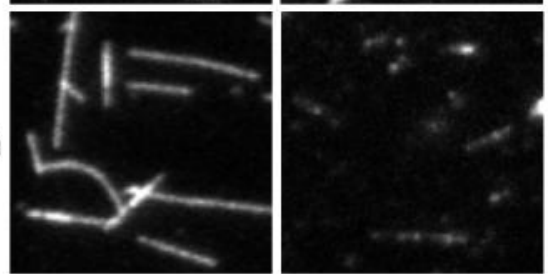
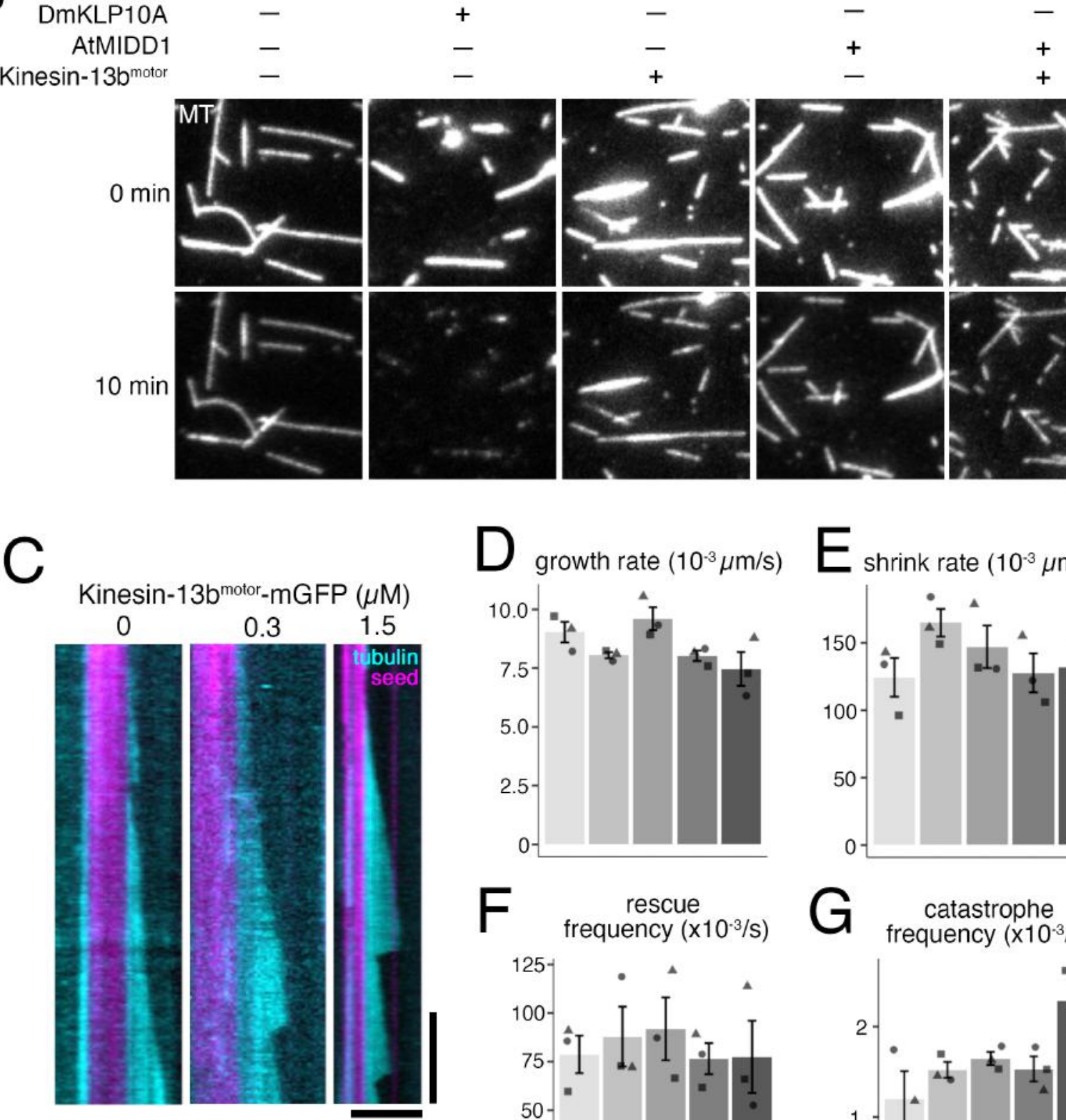

$\mathrm{D}$

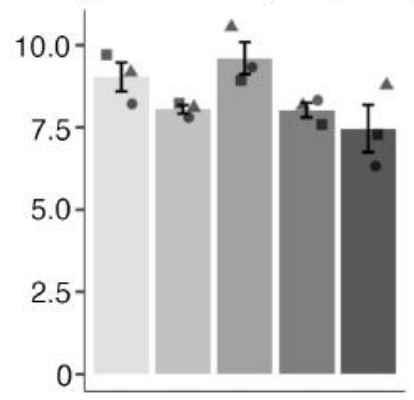

F

rescue

frequency $\left(\times 10^{-3} / \mathrm{s}\right)$

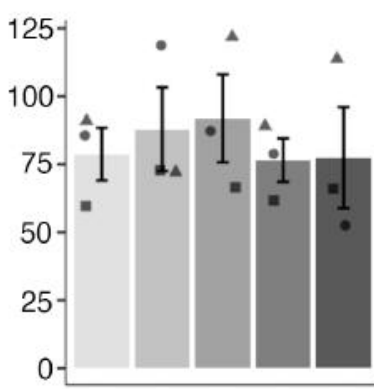

Kinesin-13b $\mathrm{b}^{\text {motor }}$-mGFP $(\mu \mathrm{M})$ :
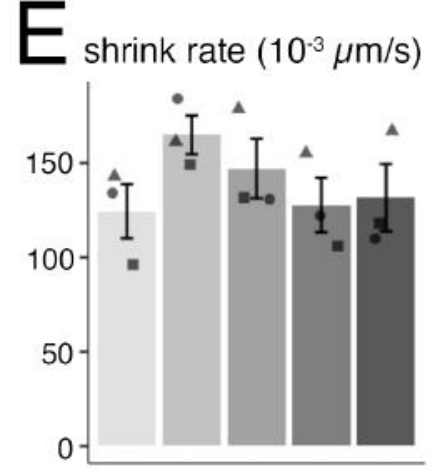

G

catastrophe frequency $\left(\times 10^{-3} / \mathrm{s}\right)$

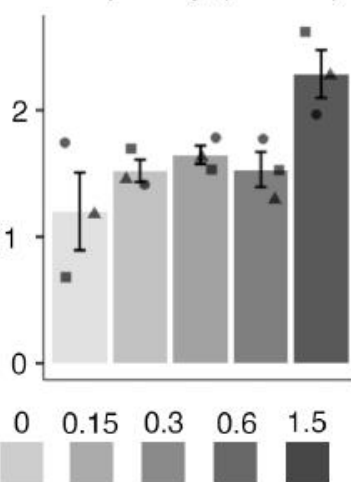

Figure 7: Recombinant Kinesin-13 does not depolymerise stabilised GMPCPP-MT seeds but shows MT catastrophe inducing activity.

(A) Protein domains of Kinesin-13b and recombinant Kinesin-13bmotor-mGFP construct. Protein domains were determined using InterPro. His-tag for affinity purification was attached to C-terminus of the recombinant protein. (B) In vitro MT depolymerisation assay using GMPCPP-stabilised MT seeds was performed using purified DmKLP10A,

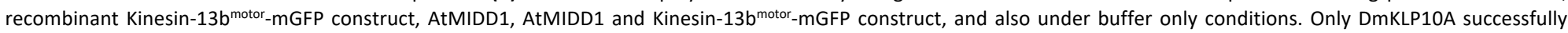
depolymerised MT seeds. The slight reduction in intensity in the bottom panels is due to photobleaching during imaging. All proteins were used at $200 \mathrm{nM}$ except for AtMIDD1 which was at $100 \mathrm{nM}$. Bar, $5 \mu \mathrm{m}$. (C) Representative kymographs of in vitro MT dynamics polymerisation assays with Kinesin-13bmotor-mGFP construct at $0,0.3$, and $1.5 \mu \mathrm{M}$. Timelapse imaging was performed with TIRF microscopy taken every $3 \mathrm{~s}$. Brightness and contrast was manually adjusted. Vertical bar, 2 min; horizontal bar; $5 \mu \mathrm{m}$. (D-G) In vitro MT

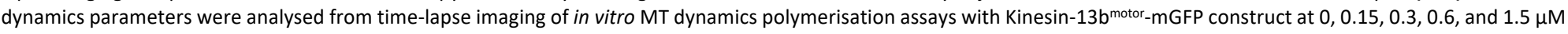
taken using TIRF microscopy at every $3 \mathrm{~s}$. In particular, growth rate was observed to reduce slightly, from $9.0 \pm 0.4 \times 10^{-3} \mu \mathrm{m} / \mathrm{s}$ (mean $\pm \mathrm{SEM} ; \mathrm{N}=3$ ) in buffer only conditions, to 7.5 $\pm 0.7 \times 10^{-3} \mu \mathrm{m} / \mathrm{s}$ (mean $\pm \mathrm{SEM} ; \mathrm{N}=3$ ) in $1.5 \mu \mathrm{M}$ protein. Catastrophe frequency was observed to reproducibly increase with high concentrations of Kinesin-13b $\mathrm{b}^{\mathrm{motor}}-\mathrm{mGFP}$, having a catastrophe frequency of $2.3 \pm 0.2 \times 10^{-3} / \mathrm{s}$ (mean $\pm \mathrm{SEM} ; \mathrm{N}=3$ ) at $1.5 \mu \mathrm{M}$ protein, compared to $1.2 \pm 0.3 \times 10^{-3} / \mathrm{s}$ in buffer only conditions. Points represent mean values from independent experiments. 


\section{Figure 8}

bioRxiv preprint doi: https://doi.org/10.1101/819722; this version posted October 28, 2019. The copyright holder for this preprint (which was not certified by peer review) is the author/funder, who has granted bioRxiv a license to display the preprint in perpetuity. It is made available under 1

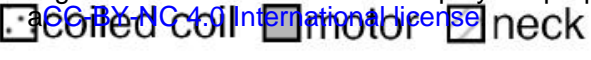

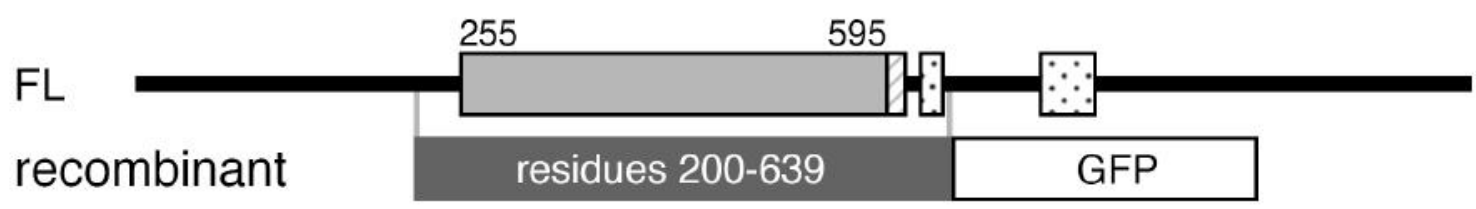

100 a.a.

B
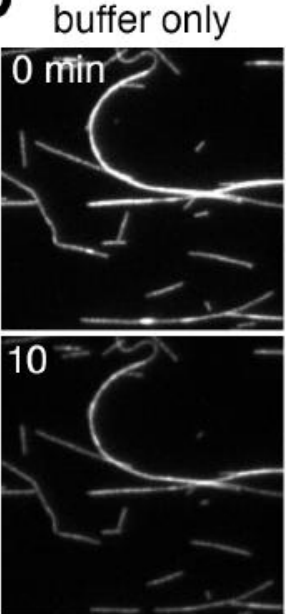

\section{ScKip3}
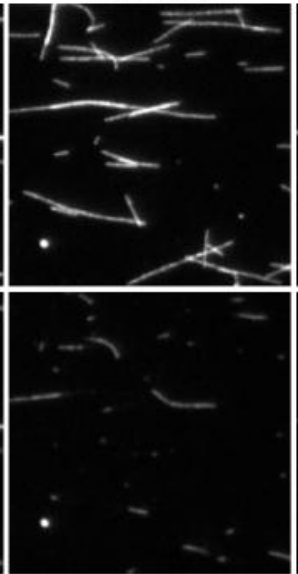

PpKinesin-8II motor

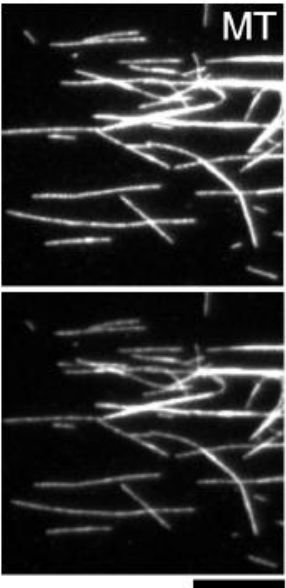

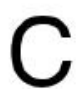
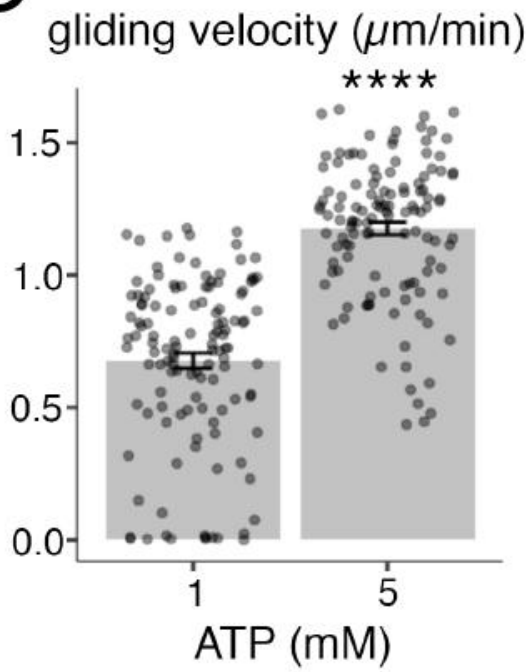

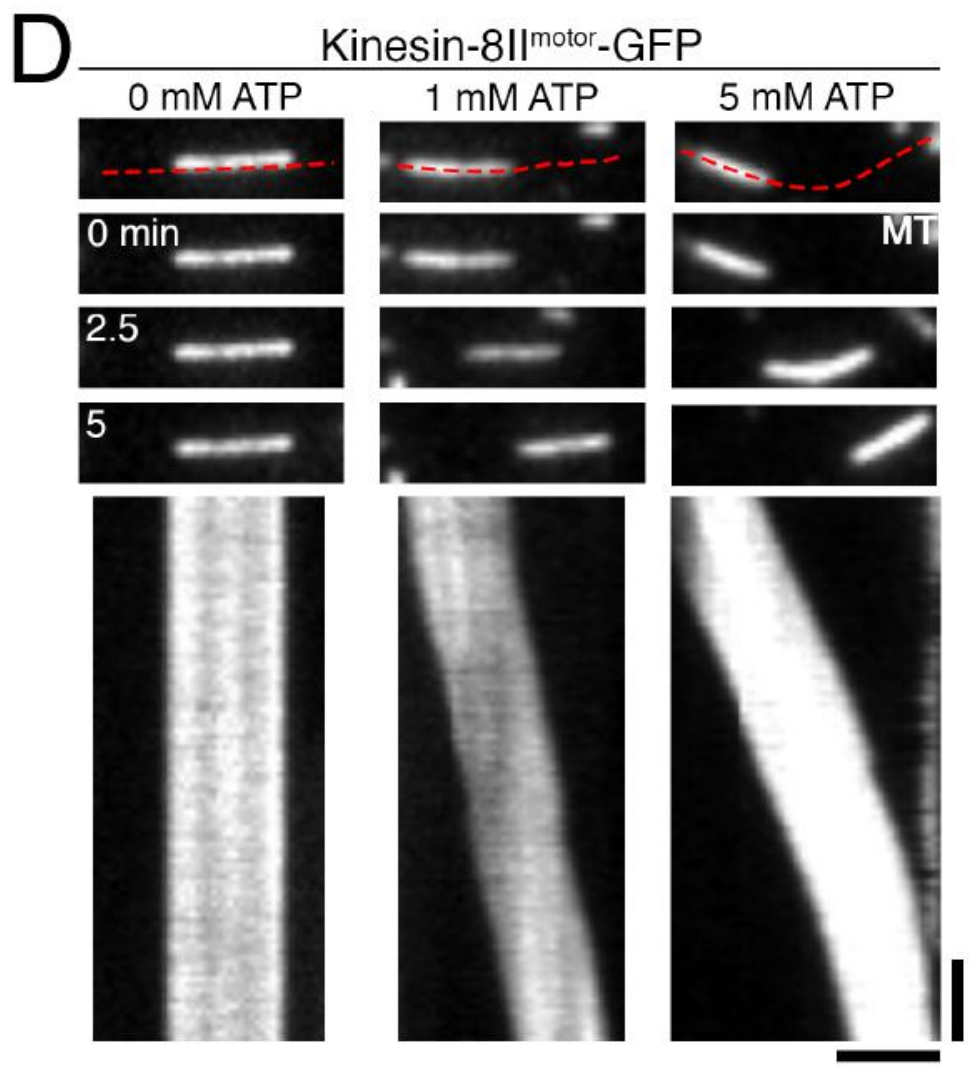

Figure 8: Recombinant Kinesin-8 motor does not depolymerise MTs but shows MT gliding activity.

(A) Protein domains of Kinesin-8II and recombinant Kinesin-8IImotor-GFP construct. Protein domains were identified using InterPro. His-tag for affinity purification was attached to C-terminus of the recombinant protein. (B) In vitro MT depolymerisation assay using GMPCPP-stabilised MT seeds was performed using purified ScKip3, recombinant Kinesin-

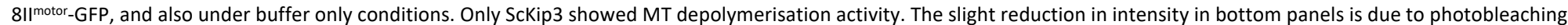
during imaging. All proteins were used at $200 \mathrm{nM}$. Bar, $10 \mu \mathrm{m}$. (C) ATP-dependent MT gliding velocity of Kinesin-8IImotor-GFP. $1 \mathrm{mM} \mathrm{ATP,} 0.68 \pm 0.03 \mu \mathrm{m} / \mathrm{min}$ (mean \pm SEM; $\mathrm{N}=$ $124 \mathrm{MTs}$ ); $5 \mathrm{mM}$ ATP, $1.18 \pm 0.02 \mu \mathrm{m} / \mathrm{min}$ (mean \pm SEM; $\mathrm{N}=121 \mathrm{MTs}$, p-value < 0.0001). (D) In vitro MT gliding assay using GMPCPP-stabilised MTs on Kinesin-8IImotor-GFP which was immobilised on glass, at 0, 1, and $5 \mathrm{mM}$ ATP. Red dotted line in top panel indicates segmented line used to draw kymographs (bottom panels). Gliding activity of Kinesin-

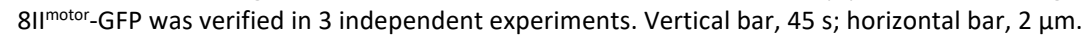




\section{Parsed Citations}

Collonnier, C., Epert, A, Mara, K., Maclot, F., Guyon-Debast, A, Charlot, F., White, C., Schaefer, D.G., and Nogue, F. (2017). CRISPRCas9-mediated efficient directed mutagenesis and RAD51-dependent and RAD51-independent gene targeting in the moss

Physcomitrella patens. Plant Biotechnol J 15, 122-131.

Pubmed: Author and Title

Google Scholar: Author Only Title Only Author and Title

Cove, D. (2005). The moss Physcomitrella patens. Annu Rev Genet 39, 339-358.

Pubmed: Author and Title

Google Scholar: Author Only Title Only Author and Title

Deng, ZY., Liu, L.T., Li, T., Yan, S., Kuang, B.J., Huang, S.J., Yan, C.J., and Wang, T. (2015). OsKinesin-13A is an active microtubule depolymerase involved in glume length regulation via affecting cell elongation. Sci Rep 5, 9457.

Pubmed: Author and Title

Google Scholar: Author Only Title Only Author and Title

Desai, A, Verma, S., Mitchison, T.J., and Walczak, C.E. (1999). Kin I kinesins are microtubule-destabilizing enzymes. Cell 96, 69-78.

Pubmed: Author and Title

Google Scholar: Author Only Title Only Author and Title

Doonan, J.H., Cove, D.J., and Lloyd, C.W. (1985). Immunofluorescence microscopy of microtubules in intact cell lineages of the moss,

Physcomitrella patens. I. Normal and CIPC-treated tip cells. J Cell Sci 75, 131-147.

Pubmed: Author and Title

Google Scholar: Author Only Title Only Author and Title

Doonan, J.H., Cove, D.J., and Lloyd, C.W. (1988). Microtubules and microfilaments in tip growth: evidence that microtubules impose polarity on protonemal growth in Physcomitrella patens. J Cell Sci 89, 533-540.

Pubmed: Author and Title

Google Scholar: Author Only Title Only Author and Title

Edzuka, T., and Goshima, G. (2019). Drosophila kinesin-8 stabilizes the kinetochore-microtubule interaction. J Cell Biol 218, 474-488.

Pubmed: Author and Title

Google Scholar: Author Only Title Only Author and Title

Eng, R.C., and Wasteneys, G.O. (2014). The microtubule plus-end tracking protein ARMADILLO-REPEAT KINESIN1 promotes microtubule catastrophe in Arabidopsis. Plant Cell 26, 3372-3386.

Pubmed: Author and Title

Google Scholar: Author Only Title Only Author and Title

Fujikura, U., Elsaesser, L., Breuninger, H., Sanchez-Rodriguez, C., Ivakov, A, Laux, T., Findlay, K., Persson, S., and Lenhard, M. (2014). Atkinesin-13Amodulates cell-wall synthesis and cell expansion in Arabidopsis thaliana via the THESEUS1 pathway. PLoS Genet 10 , e1004627.

Pubmed: Author and Title

Google Scholar: Author Only Title Only Author and Title

Ganem, N.J., Upton, K., and Compton, D.A (2005). Efficient mitosis in human cells lacking poleward microtubule flux. Curr Biol 15, 18271832.

Pubmed: Author and Title

Google Scholar: Author Only Title Only Author and Title

Gatt, M.K., Savoian, M.S., Riparbelli, M.G., Massarelli, C., Callaini, G., and Glover, D.M. (2005). Klp67Adestabilises pre-anaphase microtubules but subsequently is required to stabilise the central spindle. J Cell Sci 118, 2671-2682.

Pubmed: Author and Title

Google Scholar: Author Only Title Only Author and Title

Gell, C., Bormuth, V., Brouhard, G.J., Cohen, D.N., Diez, S., Friel, C.T., Helenius, J., Nitzsche, B., Petzold, H., Ribbe, J., Schaffer, E., Stear, J.H., Trushko, A, Varga, V., Widlund, P.O., Zanic, M., and Howard, J. (2010). Microtubule dynamics reconstituted in vitro and imaged by single-molecule fluorescence microscopy. Methods Cell Biol 95, 221-245.

Pubmed: Author and Title

Google Scholar: Author Only Title Only Author and Title

Gicking, AM., Swentowsky, K.W., Dawe, R.K., and Qiu, W. (2018). Functional diversification of the kinesin-14 family in land plants. FEBS Lett 592, 1918-1928.

Pubmed: Author and Title

Google Scholar: Author Only Title Only Author and Title

Goshima, G., and Vale, R.D. (2003). The roles of microtubule-based motor proteins in mitosis: comprehensive RNAi analysis in the Drosophila S2 cell line. J Cell Biol 162, 1003-1016.

Pubmed: Author and Title

Google Scholar: Author Only Title Only Author and Title

Goshima, G., and Scholey, J.M. (2010). Control of mitotic spindle length. Annu Rev Cell Dev Biol 26, 21-57.

Pubmed: Author and Title 
bioRxiv preprint doi: https://doi.org/10.1101/819722; this version posted October 28,2019 . The copyright holder for this preprint (which was not certified by peer review) is the author/funder, who has granted bioRxiv a license to display the preprint in perpetuity. It is made available under Google Scholar: Author Only Title Only Author and Title aCC-BY-NC 4.0 International license.

Gupta, M.L., Jr., Carvalho, P., Roof, D.M., and Pellman, D. (2006). Plus end-specific depolymerase activity of Kip3, a kinesin-8 protein, explains its role in positioning the yeast mitotic spindle. Nat Cell Biol 8, 913-923.

Pubmed: Author and Title

Google Scholar: Author Only Title Only Author and Title

Hertzer, K.M., Ems-McClung, S.C., Kline-Smith, S.L., Lipkin, T.G., Gilbert, S.P., and Walczak, C.E. (2006). Full-length dimeric MCAK is a more efficient microtubule depolymerase than minimal domain monomeric MCAK. Mol Biol Cell 17, 700-710.

Pubmed: Author and Title

Google Scholar: Author Only Title Only Author and Title

Hildebrandt, E.R., and Hoyt, M.A (2000). Mitotic motors in Saccharomyces cerevisiae. Biochim Biophys Acta $1496,99-116$.

Pubmed: Author and Title

Google Scholar: Author Only Title Only Author and Title

Hirokawa, N., Noda, Y., Tanaka, Y., and Niwa, S. (2009). Kinesin superfamily motor proteins and intracellular transport. Nat Rev Mol Cell Biol 10, 682-696.

Pubmed: Author and Title

Google Scholar: Author Only Title Only Author and Title

Hiwatashi, Y., Sato, Y., and Doonan, J.H. (2014). Kinesins have a dual function in organizing microtubules during both tip growth and cytokinesis in Physcomitrella patens. Plant Cell 26, 1256-1266.

Pubmed: Author and Title

Google Scholar: Author Only Title Only Author and Title

Homma, N., Takei, Y., Tanaka, Y., Nakata, T., Terada, S., Kikkawa, M., Noda, Y., and Hirokawa, N. (2003). Kinesin superfamily protein 2A (KIF2A) functions in suppression of collateral branch extension. Cell 114, 229-239.

Pubmed: Author and Title

Google Scholar: Author Only Title Only Author and Title

Howard, J., and Hyman, AA (2007). Microtubule polymerases and depolymerases. Curr Opin Cell Biol 19, 31-35.

Pubmed: Author and Title

Google Scholar: Author Only Title Only Author and Title

Jonsson, E., Yamada, M., Vale, R.D., and Goshima, G. (2015). Clustering of a kinesin-14 motor enables processive retrograde microtubule-based transport in plants. Nat Plants 1.

Pubmed: Author and Title

Google Scholar: Author Only Title Only Author and Title

Kline-Smith, S.L., Khodjakov, A, Hergert, P., and Walczak, C.E. (2004). Depletion of centromeric MCAK leads to chromosome congression and segregation defects due to improper kinetochore attachments. Mol Biol Cell 15, 1146-1159.

Pubmed: $\underline{\text { Author and Title }}$

Google Scholar: Author Only Title Only Author and Title

Kobayashi, T., Tsang, W.Y., Li, J., Lane, W., and Dynlacht, B.D. (2011). Centriolar kinesin Kif24 interacts with CP110 to remodel microtubules and regulate ciliogenesis. Cell 145, 914-925.

Pubmed: Author and Title

Google Scholar: Author Only Title Only Author and Title

Kofuji, R., and Hasebe, M. (2014). Eight types of stem cells in the life cycle of the moss Physcomitrella patens. Curr Opin Plant Biol 17, 13-21.

Pubmed: Author and Title

Google Scholar: Author Only Title Only Author and Title

Kosetsu, K., de Keijzer, J., Janson, M.E., and Goshima, G. (2013). MICROTUBULE-ASSOCIATED PROTEIN65 is essential for maintenance of phragmoplast bipolarity and formation of the cell plate in Physcomitrella patens. Plant Cell 25, $4479-4492$.

Pubmed: Author and Title

Google Scholar: Author Only Title Only Author and Title

Kozgunova, E., and Goshima, G. (2019). Aversatile microfluidic device for highly inclined thin illumination microscopy in the moss Physcomitrella patens. Sci Rep in press.

Pubmed: Author and Title

Google Scholar: Author Only Title Only Author and Title

Lee, T., Langford, K.J., Askham, J.M., Bruning-Richardson, A, and Morrison, E.E. (2008). MCAK associates with EB1. Oncogene 27, 2494-2500.

Pubmed: Author and Title

Google Scholar: Author Only Title Only Author and Title

Leong, S.Y., Yamada, M., Yanagisawa, N., and Goshima, G. (2018). SPIRAL2 Stabilises Endoplasmic Microtubule Minus Ends in the Moss Physcomitrella patens. Cell Struct Funct 43, 53-60.

Pubmed: Author and Title

Google Scholar: Author Only Title Only Author and Title 
bioRxiv preprint doi: https://doi.org/10.1101/819722; this version posted October 28,2019 . The copyright holder for this preprint (which was not certified by peer review) is the author/funder, who has granted bioRxiv a license to display the preprint in perpetuity. It is made available under aCC-BY-NC 4.0 International license.

Li, W., Moriwaki, T., Tani, T., Watanabe, T., Kaibuchi, K., and Goshima, G. (2012). Reconstitution of dynamic microtubules with

Drosophila XMAP215, EB1, and Sentin. J Cell Biol 199, 849-862.

Pubmed: Author and Title

Google Scholar: Author Only Title Only Author and Title

Lopez-Obando, M., Hoffmann, B., Gery, C., Guyon-Debast, A, Teoule, E., Rameau, C., Bonhomme, S., and Nogue, F. (2016). Simple and Efficient Targeting of Multiple Genes Through CRISPR-Cas9 in Physcomitrella patens. G3 (Bethesda) 6, $3647-3653$.

Pubmed: Author and Title

Google Scholar: Author Only Title Only Author and Title

Lu, L., Lee, Y.R., Pan, R., Maloof, J.N., and Liu, B. (2005). An internal motor kinesin is associated with the Golgi apparatus and plays a role in trichome morphogenesis in Arabidopsis. Mol Biol Cell 16, 811-823.

Pubmed: Author and Title

Google Scholar: Author Only Title Only Author and Title

Maney, T., Wagenbach, M., and Wordeman, L. (2001). Molecular dissection of the microtubule depolymerizing activity of mitotic centromere-associated kinesin. J Biol Chem 276, 34753-34758.

Pubmed: Author and Title

Google Scholar: Author Only Title Only Author and Title

Mayr, M.I., Hummer, S., Bormann, J., Gruner, T., Adio, S., Woehlke, G., and Mayer, T.U. (2007). The human kinesin Kif18A is a motile microtubule depolymerase essential for chromosome congression. Curr Biol 17, 488-498.

Pubmed: Author and Title

Google Scholar: Author Only Title Only Author and Title

Menand, B., Calder, G., and Dolan, L. (2007). Both chloronemal and caulonemal cells expand by tip growth in the moss Physcomitrella patens. J Exp Bot 58, 1843-1849.

Pubmed: Author and Title

Google Scholar: Author Only Title Only Author and Title

Mennella, V., Rogers, G.C., Rogers, S.L., Buster, D.W., Vale, R.D., and Sharp, D.J. (2005). Functionally distinct kinesin-13 family members cooperate to regulate microtubule dynamics during interphase. Nat Cell Biol 7, 235-245.

Pubmed: Author and Title

Google Scholar: Author Only Title Only Author and Title

Menon, S., and Gupton, S.L. (2016). Building Blocks of Functioning Brain: Cytoskeletal Dynamics in Neuronal Development. Int Rev Cell Mol Biol 322, 183-245.

Pubmed: Author and Title

Google Scholar: Author Only Title Only Author and Title

Miki, H., Okada, Y., and Hirokawa, N. (2005). Analysis of the kinesin superfamily: insights into structure and function. Trends Cell Biol 15, 467-476.

Pubmed: Author and Title

Google Scholar: Author Only Title Only Author and Title

Miki, T., Nishina, M., and Goshima, G. (2015). RNAi screening identifies the armadillo repeat-containing kinesins responsible for microtubule-dependent nuclear positioning in Physcomitrella patens. Plant Cell Physiol 56, 737-749.

Pubmed: Author and Title

Google Scholar: Author Only Title Only Author and Title

Miki, T., Nakaoka, Y., and Goshima, G. (2016). Live cell microscopy-based RNAi screening in the moss Physcomitrella patens. Methods Mol Biol 1470, 225-246.

Pubmed: Author and Title

Google Scholar: Author Only Title Only Author and Title

Miki, T., Naito, H., Nishina, M., and Goshima, G. (2014). Endogenous localizome identifies 43 mitotic kinesins in a plant cell. Proc Natl Acad Sci U S A111, E1053-1061.

Pubmed: Author and Title

Google Scholar: Author Only Title Only Author and Title

Moores, C.A, Yu, M., Guo, J., Beraud, C., Sakowicz, R., and Milligan, R.A (2002). Amechanism for microtubule depolymerization by Kinl kinesins. Mol Cell 9, 903-909.

Pubmed: Author and Title

Google Scholar: Author Only Title Only Author and Title

Moriwaki, T., and Goshima, G. (2016). Five factors can reconstitute all three phases of microtubule polymerization dynamics. J Cell Biol 215, 357-368.

Pubmed: Author and Title

Google Scholar: Author Only Title Only Author and Title

Nakaoka, Y., Kimura, A, Tani, T., and Goshima, G. (2015). Cytoplasmic nucleation and atypical branching nucleation generate endoplasmic microtubules in Physcomitrella patens. Plant Cell 27, 228-242.

Pubmed: Author and Title

Google Scholar: Author Only Title Only Author and Title 
bioRxiv preprint doi: https://doi.org/10.1101/819722; this version posted October 28, 2019. The copyright holder for this preprint (which was not certified by peer review) is the author/funder, who has granted bioRxiv a license to display the preprint in perpetuity. It is made available under aCC-BY-NC 4.0 International license.

Nakaoka, Y., Miki, T., Fujioka, R., Uehara, R., Tomioka, A, Obuse, C., Kubo, M., Hiwatashi, Y., and Goshima, G. (2012). An inducible RNA interference system in Physcomitrella patens reveals a dominant role of augmin in phragmoplast microtubule generation. Plant Cell 24, 1478-1493.

Pubmed: Author and Title

Google Scholar: Author Only Title Only Author and Title

Nebenfuhr, A, and Dixit, R. (2018). Kinesins and Myosins: Molecular Motors that Coordinate Cellular Functions in Plants. Annu Rev Plant Biol 69, 329-361.

Pubmed: Author and Title

Google Scholar: Author Only Title Only Author and Title

Niwa, S., Nakajima, K., Miki, H., Minato, Y., Wang, D., and Hirokawa, N. (2012). KIF19A is a microtubule-depolymerizing kinesin for ciliary length control. Dev Cell 23, 1167-1175.

Pubmed: Author and Title

Google Scholar: Author Only Title Only Author and Title

Oda, Y., and Fukuda, H. (2013). Rho of plant GTPase signaling regulates the behavior of Arabidopsis kinesin-13A to establish secondary cell wall patterns. Plant Cell 25, 4439-4450.

Pubmed: Author and Title

Google Scholar: Author Only Title Only Author and Title

Ogawa, T., Saijo, S., Shimizu, N., Jiang, X., and Hirokawa, N. (2017). Mechanism of Catalytic Microtubule Depolymerization via KIF2-

Tubulin Transitional Conformation. Cell Rep 20, 2626-2638.

Pubmed: Author and Title

Google Scholar: Author Only Title Only Author and Title

Ovechkina, Y., Wagenbach, M., and Wordeman, L. (2002). K-loop insertion restores microtubule depolymerizing activity of a "neckless" MCAK mutant. J Cell Biol 159, 557-562.

Pubmed: Author and Title

Google Scholar: Author Only Title Only Author and Title

Reddy, AS., and Day, I.S. (2001). Kinesins in the Arabidopsis genome: a comparative analysis among eukaryotes. BMC Genomics 2, 2.

Pubmed: Author and Title

Google Scholar: Author Only Title Only Author and Title

Rogers, G.C., Rogers, S.L., and Sharp, D.J. (2005). Spindle microtubules in flux. J Cell Sci 118, 1105-1116.

Pubmed: $\underline{\text { Author and Title }}$

Google Scholar: Author Only Title Only Author and Title

Rogers, G.C., Rogers, S.L., Schwimmer, T.A, Ems-McClung, S.C., Walczak, C.E., Vale, R.D., Scholey, J.M., and Sharp, D.J. (2004). Two mitotic kinesins cooperate to drive sister chromatid separation during anaphase. Nature 427, 364-370.

Pubmed: Author and Title

Google Scholar: Author Only Title Only Author and Title

Rounds, C.M., and Bezanilla, M. (2013). Growth mechanisms in tip-growing plant cells. Annu Rev Plant Biol 64, $243-265$.

Pubmed: Author and Title

Google Scholar: Author Only Title Only Author and Title

Sabry, J.H., O'Connor, T.P., Evans, L., Toroian-Raymond, A, Kirschner, M., and Bentley, D. (1991). Microtubule behavior during guidance of pioneer neuron growth cones in situ. J Cell Biol 115, 381-395.

Pubmed: Author and Title

Google Scholar: Author Only Title Only Author and Title

Sbalzarini, I.F., and Koumoutsakos, P. (2005). Feature point tracking and trajectory analysis for video imaging in cell biology. J Struct Biol 151, 182-195.

Pubmed: Author and Title

Google Scholar: Author Only Title Only Author and Title

Schmidt, S., and Smertenko, A (2019). Identification and characterization of the land-plant-specific microtubule nucleation factor MACET4. J Cell Sci 132.

Pubmed: Author and Title

Google Scholar: Author Only Title Only Author and Title

Shen, Z, Collatos, AR., Bibeau, J.P., Furt, F., and Vidali, L. (2012). Phylogenetic analysis of the Kinesin superfamily from physcomitrella. Front Plant Sci 3, 230.

Pubmed: Author and Title

Google Scholar: Author Only Title Only Author and Title

Shipley, K., Hekmat-Nejad, M., Turner, J., Moores, C., Anderson, R., Milligan, R., Sakowicz, R., and Fletterick, R. (2004). Structure of a kinesin microtubule depolymerization machine. EMBO J 23, 1422-1432.

Pubmed: Author and Title

Google Scholar: Author Only Title Only Author and Title

Soppina, V., and Verhey, K.J. (2014). The family-specific K-loop influences the microtubule on-rate but not the superprocessivity of kinesin-3 motors. Mol Biol Cell 25, 2161-2170. 
bioRxiv preprint doi: https://doi.org/10.1101/819722; this version posted October 28,2019 . The copyright holder for this preprint (which was not certified by peer review) is the author/funder, who has granted bioRxiv a license to display the preprint in perpetuity. It is made available under

Pubmed: Author and Title aCC-BY-NC 4.0 International license.

Google Scholar: Author Only Title Only Author and Title

Stumpff, J., von Dassow, G., Wagenbach, M., Asbury, C., and Wordeman, L. (2008). The kinesin-8 motor Kif18A suppresses kinetochore movements to control mitotic chromosome alignment. Dev Cell 14, 252-262.

Pubmed: Author and Title

Google Scholar: Author Only Title Only Author and Title

Stumpff, J., Wagenbach, M., Franck, A, Asbury, C.L., and Wordeman, L. (2012). Kif18A and chromokinesins confine centromere movements via microtubule growth suppression and spatial control of kinetochore tension. Dev Cell 22, 1017-1029.

Pubmed: Author and Title

Google Scholar: Author Only Title Only Author and Title

Tanaka, E., Ho, T., and Kirschner, M.W. (1995). The role of microtubule dynamics in growth cone motility and axonal growth. J Cell Biol 128, 139-155.

Pubmed: Author and Title

Google Scholar: Author Only Title Only Author and Title

Uehara, R., Tsukada, Y., Kamasaki, T., Poser, I., Yoda, K., Gerlich, D.W., and Goshima, G. (2013). Aurora B and Kif2A control microtubule length for assembly of a functional central spindle during anaphase. J Cell Biol 202, 623-636.

Pubmed: Author and Title

Google Scholar: Author Only Title Only Author and Title

Unsworth, A, Masuda, H., Dhut, S., and Toda, T. (2008). Fission yeast kinesin-8 KIp5 and KIp6 are interdependent for mitotic nuclear retention and required for proper microtubule dynamics. Mol Biol Cell 19, 5104-5115.

Pubmed: Author and Title

Google Scholar: Author Only Title Only Author and Title

Vidali, L., Augustine, R.C., Kleinman, K.P., and Bezanilla, M. (2007). Profilin is essential for tip growth in the moss Physcomitrella patens. Plant Cell 19, 3705-3722.

Pubmed: Author and Title

Google Scholar: Author Only Title Only Author and Title

Walczak, C.E., and Heald, R. (2008). Mechanisms of Mitotic Spindle Assembly and Function 265, 111-158.

Pubmed: Author and Title

Google Scholar: Author Only Title Only Author and Title

Walczak, C.E., Gayek, S., and Ohi, R. (2013). Microtubule-depolymerizing kinesins. Annu Rev Cell Dev Biol 29, $417-441$.

Pubmed: Author and Title

Google Scholar: Author Only Title Only Author and Title

West, R.R., Malmstrom, T., Troxell, C.L., and McIntosh, J.R. (2001). Two related kinesins, klp5+ and klp6+, foster microtubule disassembly and are required for meiosis in fission yeast. Mol Biol Cell 12, 3919-3932.

Pubmed: Author and Title

Google Scholar: Author Only Title Only Author and Title

Wu, S.Z, and Bezanilla, M. (2018). Actin and microtubule cross talk mediates persistent polarized growth. J Cell Biol 217, $3531-3544$. Pubmed: Author and Title

Google Scholar: Author Only Title Only Author and Title

Yamada, M., and Goshima, G. (2018). The KCH Kinesin Drives Nuclear Transport and Cytoskeletal Coalescence to Promote Tip Cell Growth in Physcomitrella patens. Plant Cell 30, 1496-1510.

Pubmed: Author and Title

Google Scholar: Author Only Title Only Author and Title

Yamada, M., Miki, T., and Goshima, G. (2016). Imaging Mitosis in the Moss Physcomitrella patens. Methods Mol Biol 1413, $263-282$. Pubmed: Author and Title

Google Scholar: Author Only Title Only Author and Title

Yoshida, M.W., Yamada, M., and Goshima, G. (2019). Moss Kinesin-14 KCBP Accelerates Chromatid Motility in Anaphase. Cell Struct Funct 44, 95-104.

Pubmed: Author and Title

Google Scholar: Author Only Title Only Author and Title

Movie legends

Movie 1. Mitosis of control, Kinesin-13, and Kinesin-8 KO moss

GFP-tubulin and histoneH2B-mRFP were imaged with spinning disc confocal microscopy. NEBD, 0 min; Playback at 10 fps at 1 min intervals; left, basal side; right, apical side.

Movie 2. Spindle poleward flux of control and Kinesin-13 KO moss

GFP-tubulin on the mitotic spindle at metaphase was photobleached in a strip $(0 \mathrm{~min})$, and the migration of the photobleached strip towards the poles can be observed. Playback at $20 \mathrm{fps}$ at $3 \mathrm{~s}$ intervals. 
bioRxiv preprint doi: https://doi org/10.1101/819722. this version posted October 28,2019 . The copyright holder for this preprint (which was not certified by peer review) is the author/funder, who has granted bioRxiv a license to display the preprint in perpetuity. It is made available under Movie 3. Protonema filament growth of control, Kinesin-13 and $-8 \mathrm{KO}$ moss.

GFP-tubulin was imaged with epifluorescence microscopy. Playback at $30 \mathrm{fps}$ at $3 \mathrm{~min}$ intervals.

Movie 4. MT foci in protonema growth of control, Kinesin-13 and -8 KO moss

The MT foci was imaged with spinning disc confocal microscopy. Movies are maximumz-projections of z-stacks taken every $0.3 \mu \mathrm{m}$ for a $20 \mu \mathrm{m}$ range. Playback at $15 \mathrm{fps}$ at 3 min intervals.

Movie 5. Localisation of Kinesin-13 during interphase

Kinesin-13c is shown representatively for the other two paralogues, which show similar localisation. Localisation at the MT foci (top panel) and the interphase endoplasmic MT array (bottom panel) were imaged with spinning disc confocal microscopy and oblique illumination fluorescence microscopy respectively. Playback at $15 \mathrm{fps}$ at $3 \mathrm{~s}$ intervals. 